\author{
Federal Reserve Bank of New York \\ Staff Reports
}

\title{
Information Acquisition and Financial Intermediation
}

Nina Boyarchenko

Staff Report No. 571

September 2012

Revised June 2014

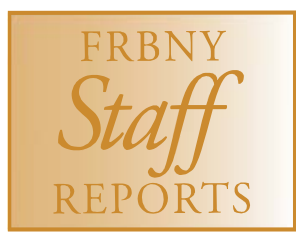

This paper presents preliminary findings and is being distributed to economists and other interested readers solely to stimulate discussion and elicit comments. The views expressed in this paper are those of the author and do not necessarily reflect the position of the Federal Reserve Bank of New York or the Federal Reserve System. Any errors or omissions are the responsibility of the author. 


\author{
Information Acquisition and Financial Intermediation \\ Nina Boyarchenko \\ Federal Reserve Bank of New York Staff Reports, no. 571 \\ September 2012; revised June 2014 \\ JEL classification: G12, G19, E44, G00
}

\begin{abstract}
Informational advantages of specialists relative to households lead to disagreement between the two in an intermediated market. Although households can acquire additional signals to reduce the informational asymmetry, the additional information is costly, making it rational for households to limit the accuracy of the signals they observe. I show that this leads the equity capital constraint to bind more frequently, making the asset prices in the economy more volatile unconditionally. When disagreement between households and specialists is high, however, return volatility decreases. I find empirical evidence consistent with these predictions.
\end{abstract}

Keywords: financial intermediation, rational inattention, disagreement

Boyarchenko: Federal Reserve Bank of New York (e-mail: nina.boyarchenko@ny.frb.org).The author would like to thank Charles Calomiris (editor), an anonymous referee, Tobias Adrian, Valentin Haddad, Or Shachar, Pietro Veronesi, and participants in the Deutsche Bank Symposium on Risk Management. The author also thanks the Financial Intermediation department for comments on the previous version of this paper. The views expressed in this paper are those of the author and do not necessarily reflect the position of the Federal Reserve Bank of New York or the Federal Reserve System. 


\section{Introduction}

Standard theories of intermediated markets postulate that specialists have access to better information about risky assets than households and are thus able to invest in risky asset markets. This paper explicitly models this consideration in an intermediated market model of the economy, and allows households to decrease the information gap with the specialists by acquiring additional signals about the fundamentals in the economy. I

find that differences in beliefs between the specialists and the households lead to more frequent periods of intermediation capital shortages, and thus, unconditionally, more volatile asset prices. Further, as disagreement between households and specialists increases, the equity risk premium increases but the return volatility decreases.

My model builds on the model of financial intermediation of He and Krishnamurthy $(2012,2013)$. There are two types of agents in the economy: specialists and households. While the specialists have access to the risky asset market, households cannot invest directly in the risky asset. The two types of agents thus enter into an intermediation contract, with the specialists investing in the risky asset on behalf of the households. As in $\mathrm{He}$ and Krishnamurthy (2013), the intermediation relation is subject to an equity constraint, with the households unwilling to commit funds greater than given multiple of specialist wealth, ensuring that the specialists have "skin in the game".

The asset markets in the economy are modeled along the lines of Lucas (1978). There is a risky asset producing an exogenous but risky dividend stream. While the specialists can invest in the risky asset directly, the households cannot. Both types of agents in the economy can, however, lend and borrow through investing in (or, correspondingly, shorting) a riskless bond. The point of departure of this model from the previous literature is that the households in this economy do not know the expected dividend growth rate. Instead, they use observations of dividends to learn about the true expected dividend growth rate. In addition, the households also have access to an external signal but face a capacity con- 
straint in processing the information contained in the signal. Households thus optimally choose to acquire low precision signals, and, thus, remain at an informational disadvantage relative to the specialists. This is consistent with the evidence in Hong, Torous, and Valkanov (2007), who show that even sophisticated investors are inattentive to important economic news.

The differences in learning technologies lead to disagreement between the specialists and the households. While the differences in beliefs influence the total wealth of the intermediary (through the optimal allocation decisions of the household) and, thus, the behavior of asset prices in the economy, unlike the setting of Scheinkman and Xiong (2003), this disagreement does not lead to asset price bubbles. Intuitively, the risky assets in the economy are always held by the intermediary sector. Thus, even though there is disagreement between the specialists and the households, there is no resale motive in setting asset prices and bubbles do not occur. The risk premium and the Sharpe ratio of the risky asset increase as disagreement increases, but the return volatility decreases. When the households are more pessimistic, they have to be compensated more for holding (indirectly) the risky asset, increasing the risk premium. Since household participation in the intermediary decreases as they become more pessimistic, there is less wealth invested in the risky asset, decreasing return volatility and increasing the Sharpe ratio.

I test the main empirical predictions of the model, and find that these are borne out in the data. I proxy for household wealth by the total financial wealth of the households from Flow of Funds Table L.100, and disagreement by the interquartile range of forecasts of GDP growth from the Survey of Professional Forecasters. Household wealth consistently increases the risk premium in the S\&P 500, and decreases both implied and realized volatility. During booms, disagreement increase risk premia and decreases volatility. During recessions, disagreement has little impact on either the equity risk premium or volatility.

The disagreement between specialists and households also impacts the shape of the 
intermediation-constrained region in the economy. In particular, while it is still true that the economy is intermediation-constrained when the household's wealth is large relative to that of the specialist, when the household is more optimistic than the specialist, the critical level of the relative wealth of the household decreases. Intuitively, when the household is more optimistic, it would like to invest a larger fraction of its wealth in the risky asset, allocating a larger fraction of its wealth to the intermediary. Notice that, since both the specialist and the household are myopic in this economy, the household does not take into account the fact that the specialist has more precise information when making its portfolio allocation decision.

This paper links the recent literature on financial intermediation in a macroeconomic setting with the literature on economic agents' limited capacity to process information, or rational inattention. The economic literature on rational inattention builds on the seminal papers by Sims $(2003,2006)$. The main premise of the rational inattention literature is that agents face a cost in processing the signals available to them in the public markets and thus optimally choose to observe only some of the information potentially available to them. The cost of information can either be a physical cost, with the agents limited in the rate of information transmission that they can process, or a monetary cost, increasing in the information transmission rate demanded by the agent. The current paper falls in the latter category, with the specialists in the economy paying a monetary cost out of their own wealth for observing more precise external signals. The information choice setting in this paper is closest to Detemple and Kihlstrom (1987) and Huang and Liu (2007). While both of these papers take the dynamics of asset prices in the economy as given and study the optimal portfolio choice problem of an investor faced with information acquisition costs, Huang and Liu (2007) solve the date zero optimal information choice while Detemple and Kihlstrom (1987) allow the agent in the economy to dynamically update his information choice. Huang and Liu (2007) show that rational inattention may cause the representative investor to over- or underinvest. Furthermore, the optimal trading 
strategy is myopic with respect to future information choices.

van Nieuwerburgh and Veldkamp (2010) and Kacperczyk, van Nieuwerburgh, and Veldkamp (2011) study the optimal portfolio and attention allocation between multiple assets. van Nieuwerburgh and Veldkamp (2010) show that, given a fixed capacity to process information about expected asset returns, the investor that collects information before choosing the optimal portfolio allocation will systematically deviate from holding a diversified portfolio and may choose to invest instead in a diversified fund and a concentrated set of assets. In a similar setting, Kacperczyk et al. (2011) show that mutual fund managers optimally alter their information choice based on the state of the economy, leading to higher correlation of fund portfolio holdings with the aggregate information, higher dispersion in returns across funds and higher average fund performance in recessions than in expansions. Unlike the current paper, the fund managers of Kacperczyk et al. (2011) face a capacity constraint in information acquisition. Thus, the information friction in their paper can be interpreted as differences in skill between different fund managers. This paper differs from the above literature in that the model is dynamic, and asset prices are determined in equilibrium.

This paper is also related to the large literature in banking studying (dis)intermediation. While traditional models consider the problem in a static setting (see Diamond and Dybvig (1983); Allen and Gale (1994); Holmstrom and Tirole (1997); Diamond and Rajan (2005)), the more recent work (see e.g. He and Krishnamurthy (2012, 2013); Brunnermeier and Sannikov (2013); Haddad (2012)) studies the links between financial intermediation and asset prices in a dynamic setting. These papers, however, assume that the factors underlying aggregate output (and, hence, prices) in the economy are perfectly observed.

The rest of the paper is organized as follows. Section 2 presents the economic environment faced by the agents in the economy. The equilibrium behavior of asset prices is examined in Section 3. I provide some motivation empirical evidence in Section 4. Section 5 concludes. Technical details are relegated to the appendix. 


\section{The Model}

In this section, I describe the environment faced by the agents in the economy. Starting with the financial intermediation setting of He and Krishnamurthy (2013), I consider the case of imperfect information and the incentives to acquire more precise information.

\subsection{Economic environment}

In this paper, I consider a version of the Lucas (1978) endowment economy. There are two types of assets traded in asset markets: a risk-free bond in zero net supply, with (locally) risk less rate $r_{t}$ and a risky asset in unitary supply. The risky asset is a claim to the dividends of the Lucas tree, with risky dividend growth given by:

$$
\frac{d D_{t}}{D_{t}}=g_{t} d t+\sigma_{d} d Z_{d t}
$$

where $D_{0}$ is known by the agents in the economy, $\sigma_{d}>0$ are constants, and $d Z_{t}$ is the increment of the standard Brownian motion under the appropriate filtration. The expected dividend growth rate $g_{t}$ is time-varying and evolves according to a mean-reverting process:

$$
d g_{t}=\kappa_{g}\left(\bar{g}-g_{t}\right) d t+\sigma_{g} d Z_{g t}
$$

where $\kappa_{g}, \bar{g}$ and $\sigma_{g}$ constants, and $d Z_{g t}$ is the increment of the standard Brownian motion, independent of $d Z_{d t}$. Notice that this specification corresponds to the continuous-time version of the long-run specification of aggregate consumption growth dynamic of Bansal and Yaron (2004). The mean-reverting expected dividend growth rate $g_{t}$ corresponds to the long-run component of consumption growth in their specification; since the model in question is a general equilibrium model, aggregate dividends correspond to aggregate consumption. Denoting by $P_{t}$ the price of the risky asset at time $t \geq 0$, the risky asset total 
return is given by:

$$
d R_{t}=\frac{D_{t} d t+d P_{t}}{P_{t}}
$$

There are two types of agents in the economy, each of unit mass: households and specialists. As in He and Krishnamurthy $(2013,2012)$, I assume that the households cannot invest directly in the risky asset. This corresponds to the assumptions usually made in the literature on limited market participation (see e.g. Allen and Gale (1994); Basak and Cuoco (1998); Mankiw and Zeldes (1991); Vissing-Jorgensen (2002)) and is usually motivated by appealing to "informational" transaction costs that households face in order to invest directly in the risky asset market. While I do not investigate the optimal occupation choice, I make a step in that direction by allowing the specialists to have access to a better learning technology.

To circumvent the limited participation constraint, at each time $t>0$, households and specialists are randomly matched to create a short-lived (lasting from time $t$ to $t+d t$ ) intermediary. The intermediary is subject to an equity constraint. In particular, denoting by $w_{t}$ the time $t$ wealth of the specialist and by $H_{t}$ the time $t$ contribution of the household to the intermediary, the equity constraint stipulates that:

$$
H_{t} \leq m w_{t}
$$

That is, the household can only contribute up to a multiple $m$ of specialist wealth to the intermediary. As in He and Krishnamurthy (2013), I assume that the specialist contributes all of his wealth to the intermediary, and that the intermediary profits are distributed between the specialist and the household in proportion to their relative wealth contributions.

Both the specialist and the household evaluate consumption paths using the log utility 
function. With this assumption, the expected lifetime utility of the specialist is given by:

$$
\mathbb{E}\left[\int_{0}^{+\infty} e^{-\rho t} \log c_{t} d t\right]
$$

where $\rho$ is the time discount rate of agents in the economy and $c_{t}$ is the specialist's consumption rate at time $t$, and the expected lifetime utility of the household is given by:

$$
\mathbb{E}\left[\int_{0}^{+\infty} e^{-\rho t} \log c_{h t} d t\right]
$$

where $c_{h t}$ is the household's consumption rate at time $t$.

\subsection{Learning}

In this paper, I model explicitly the informational advantage of the specialist and assume that, while the specialists observe the true value of the expected dividend growth rate $g_{t}$, the households do not. ${ }^{1}$ Instead, the households use observations of the realized dividend growth process to learn about $g_{t}$. In addition, households can observe an external, unbiased signal of the expected dividend growth rate of the form:

$$
d e_{t}=g_{t} d t+\frac{\sigma_{e}}{\sqrt{n_{t}}} d Z_{e t}
$$

where $\sigma_{e}>0$ is a constants, $n_{t}$ denotes the effort expanded by the specialist in acquiring information and $d Z_{e t}$ is the increment of the standard Brownian motion, independent of both $d Z_{d t}$ and $d Z_{g t}$. Below, I formulate the optimal information choice problem for the households. I begin, however, by studying the properties of the households' beliefs for a given sequence of signal precisions, $\left\{n_{t}\right\}_{t \geq 0}$. The following result holds.

\footnotetext{
${ }^{1}$ I assume that the specialists observe the value of the expected dividend growth for simplicity. An alternative specification where both the households and the specialists solve a learning problem but the specialists have access to a better information acquisition technology would lead to similar implications for equilibrium asset prices.
} 


\section{Lemma 1. (Kalman-Bucy Filter)}

Given the time $t$ information set $\mathcal{G}_{t}=\sigma^{-}\left\{D_{s}, e_{s}: s \leq t\right\}$, the household's inference at time $t$ of the expected dividend growth rate has a Gaussian distribution: $g_{t} \mid \mathcal{G}_{t} \sim N\left(\hat{g}_{t}, \gamma_{t}\right)$, with the inferred growth rate $\hat{g}_{t}$ evolving according to:

$$
d \hat{g}_{t}=\kappa_{g}\left(\bar{g}-\hat{g}_{t}\right) d t+\frac{\gamma_{t}}{\sigma_{d}} d \tilde{Z}_{d t}+\frac{\gamma_{t} \sqrt{n_{t}}}{\sigma_{e}} d \tilde{Z}_{e t},
$$

and the conditional variance of the belief as:

$$
\frac{d \gamma_{t}}{d t}=-2 \kappa_{g} \gamma_{t}+\sigma_{g}^{2}-\gamma_{t}^{2}\left(\frac{1}{\sigma_{d}^{2}}+\frac{n_{t}}{\sigma_{e}^{2}}\right) .
$$

Here, $d \tilde{Z}_{d t}$ and $d \tilde{Z}_{e t}$ are independent increments of the standard Brownian motion under $\mathcal{G}_{t}$, given, respectively, by:

$$
\begin{aligned}
& d \tilde{Z}_{d t}=\sigma_{d}^{-1}\left(\frac{d D_{t}}{D_{t}}-\hat{g}_{t} d t\right) \\
& d \tilde{Z}_{e t}=\frac{\sqrt{n_{t}}}{\sigma_{e}}\left(d e_{t}-\hat{g}_{t} d t\right) .
\end{aligned}
$$

Proof. See e.g. Theorem 10.2 of Liptser and Shiryaev (1977).

The above filter has intuitive properties. First, for a given precision of the external signal $n_{t}$, the households learn faster (that is, the variance of their beliefs $\gamma_{t}$ decreases) if dividends are a more precise signal of the expected dividend growth rate, so that $\sigma_{d}$ is small, or the expected dividend growth rate mean-reverts faster, so that $\kappa_{g}$ is large. Second, the inferred expected dividend growth rate $\hat{g}_{t}$ mean-reverts to the unconditional mean $\bar{g}$ with the same speed that the true expected dividend growth rate $g_{t}$ does. Unlike the true dividend growth rate, however, the process for $\hat{g}_{t}$ has time-varying volatility (through $\gamma_{t}$ ) and, depending on the choice of $n_{t}$, can have stochastic volatility. Finally, as pointed out in Collin-Dufresne, Johannes, and Lochstoer (2013), in the case of a constant 
expected dividend growth rate (so that $g_{t}=\bar{g}$ for all $t \geq 0$ ), learning introducing timevariation into the dividend growth process, with truly long-run risks, as the households perceive dividend shocks to be permanent. Indeed, under the households' information set $\mathcal{G}_{t}$, dividend growth evolves as

$$
\frac{d D_{t}}{D_{t}}=\hat{g}_{t} d t+\sigma_{d} d \tilde{Z}_{d t} .
$$

For the case of constant expected dividend growth rate under the full information set, $\hat{g}_{t}$ is a Brownian motion with zero mean, corresponding to a unit root process for the perceived expected dividend growth.

Turn now to the optimal information choice faced by the households. I assume that the households face a capacity constraint in processing the external signal, with the total information transmission rate to the household from observations of both the realized dividend growth rate $d D_{t} / D_{t}$ and the external signal bounded above by a constant. As in Sims $(2003,2006)$, this can be interpreted as a physical constraint in processing information. This friction prevents the household from "growing out" of the information constraint as its wealth increases. In this paper, I assume that the households do not face a monetary cost when observing the external signal. Thus, rational inattention affects equilibrium outcomes only through household beliefs, and not through the household budget constraint. Boyarchenko and Duarte (2012) discuss different specifications of the information acquisition trade off and their impact on equilibrium outcomes. To formulate the capacity constraint, I will use the following definition.

Definition 1. (Mutual Information) Let $x$ and $y$ be two random processes on the real line, and denote by $\mu_{x}, \mu_{y}, \mu_{x, y}$ the probability measures induced on the canonical space $(\Omega, \mathcal{G})$ by $x, y$ and $(x, y)$ respectively. Then, the mutual information between processes $x$ and $y$ over the time interval 
$[0, t]$ is

$$
\mathcal{I}_{t}(x, y)=\mathbb{E}\left[\log \frac{d \mu_{x, y}^{t}}{d\left[\mu_{x}^{t} \times \mu_{y}^{t}\right]}(x, y)\right]
$$

where $\mu^{t}$. is the restriction to $\mathcal{G}_{t}$ and $\mu_{x}^{t} \times \mu_{y}^{t}$ is the Cartesian product of the corresponding measures.

Thus, the mutual information between two random processes is the Kullback-Leibler divergence between the joint distribution $\mu_{x, y}$ and the product of the two marginal distributions $\mu_{x} \times \mu_{y}$. When the two processes are independent, the mutual information is zero. Given the Gaussian structure ${ }^{2}$ of the observation-state system described in Lemma 1, the information encoded in the history (up to time $t$ ) of the signal vector $s^{t}=\left[D^{t} e^{t}\right]^{\prime}$ about the history of the expected dividend growth rate $g^{t}$ can be expressed as

$$
\mathcal{I}_{t}(g, s)=\mathbb{E}\left[\log \frac{d \mu_{g, s}}{d\left[\mu_{g} \times \mu_{s}\right]}\left(g^{t}, s^{t}\right) \mid \mathcal{G}_{t}\right]=\frac{1}{2} \int_{0}^{t} \mathbb{E}\left[\left(g_{s}-\hat{g}_{s}\right)^{2}\left(\frac{1}{\sigma_{d}^{2}}+\frac{n_{s}}{\sigma_{e}^{2}}\right) \mid \mathcal{G}_{t}\right] d s .
$$

For a proof of the above result, see e.g. Turmuhambetova (2005).

The capacity constraint limits the per-period information transmission rate to the households, with the later given by:

$$
\frac{d \mathcal{I}_{t}}{d t}(g, s)=\frac{1}{2} \mathbb{E}\left[\left(g_{t}-\hat{g}_{t}\right)^{2}\left(\frac{1}{\sigma_{d}^{2}}+\frac{n_{t}}{\sigma_{e}^{2}}\right) \mid \mathcal{G}_{t}\right]=\frac{\gamma_{t}}{2}\left(\frac{1}{\sigma_{d}^{2}}+\frac{n_{t}}{\sigma_{e}^{2}}\right) .
$$

Thus, for a given level of the precision $\gamma_{t}^{-1}$ of the households' beliefs, the information transmission rate is higher when the households exert more effort and choose a higher $n_{t}$. Conversely, for a given effort choice $n_{t}$, the information transmission rate is higher if the precision $\gamma_{t}^{-1}$ of beliefs is lower. Intuitively, while the households are relatively unin-

\footnotetext{
${ }^{2}$ Given the strategic choice to acquire information, it is not immediate that standard filtering results apply. Detemple and Kihlstrom (1987), however, show that, even with strategic information choice, the households's beliefs are given by the Kalman-Bucy filter.
} 
formed about the expected dividend growth rate, even signals with low precision carry sufficient information to improve the precision of the households' posterior beliefs. As the households become more informed, signals need to be more precise to convey additional information to the households. With a capacity constraint, the information transmission rate is bounded above by a constant $\kappa>0$, so that the households' information processing constraint is given by

$$
\frac{d \mathcal{I}_{t}}{d t}(g, s) \leq \kappa \quad \forall t \geq 0
$$

Introduce $f_{t}=g_{t}-\hat{g}_{t}$ to be the disagreement between the specialist and the household about the expected dividend growth rate. Under the specialists' (full) information set $\mathcal{F}_{t}=\sigma^{-}\left\{D_{s}, e_{s}, g_{s}: s \leq t\right\}$, disagreement evolves as:

$$
d f_{t}=-\left(\kappa_{g}+\frac{\gamma_{t}}{\sigma_{d}^{2}}+\frac{\gamma_{t} n_{t}}{\sigma_{e}^{2}}\right) f_{t} d t+\sigma_{g} d Z_{g t}-\frac{\gamma_{t}}{\sigma_{d}} d Z_{d t}-\frac{\gamma_{t} \sqrt{n_{t}}}{\sigma_{e}} d Z_{e t}
$$

Thus, disagreement follows a mean-reverting process, with the speed of mean-reversion determined by the information transmission rate to the household. When households use the full capacity of the information transmission channel available to them, so that

$$
\frac{d \mathcal{I}_{t}}{d t}(g, s)=\frac{\gamma_{t}}{2}\left(\frac{1}{\sigma_{d}^{2}}+\frac{n_{t}}{\sigma_{e}^{2}}\right)=\kappa
$$

the speed of mean reversion of disagreement is constant and equal to $\kappa_{g}+2 \kappa$. As households' capacity to process information increases, disagreement mean-reverts quicker to its unconditional mean of 0 . Notice that, unlike the exogenous information setting of Scheinkman and Xiong (2003), the volatility of the disagreement process is time varying, and depends on the precision of the households' beliefs and their effort to acquire information. When the households have low precision of their beliefs, so that $\gamma_{t}$ is large, disagreement is negatively correlated with innovations to the dividend growth process. 
The disagreement between specialists and households can be represented as a belief distortion on the part of the households. In particular, let $\mathbb{P}$ be the probability measure induced by the full information set $\mathcal{F}$ and $\tilde{\mathbb{P}}$ be the probability measure induced by the partial information set $\mathcal{G}$. The Radon-Nikodym derivative of $\tilde{\mathbb{P}}$ with respect to $\mathbb{P}$, which measures the disparity between the probability measure used by the households and that used by the specialists, is given by

$$
\mathcal{M}_{t} \equiv\left(\frac{d \tilde{\mathbb{P}}}{d \mathbb{P}}\right)_{t}=\exp \left(-\frac{1}{2} \int_{0}^{t}\left(\frac{1}{\sigma_{d}^{2}}+\frac{n_{s}}{\sigma_{e}^{2}}\right) f_{s}^{2} d s-\int_{0}^{t} \frac{f_{s}}{\sigma_{d}} d Z_{d s}-\int_{0}^{t} \frac{\sqrt{n_{s}}}{\sigma_{e}} f_{s} d Z_{e s}\right)
$$

If the disagreement between households and specialists does not vanish in the long run, the measures $\mathbb{P}$ and $\tilde{\mathbb{P}}$ are not mutually absolutely continuous. However, since $\tilde{\mathbb{P}}$ can be constructed from $\mathbb{P}$ through the Radon-Nikodym derivative $\mathcal{M}$, the households and the specialists agree on zero-probability finite-horizon events. Using $\mathcal{M}$, the households' partial information problem can be rewritten as a full-information problem, where the households evaluate consumption paths according to

$$
\mathbb{E}\left[\int_{0}^{+\infty} e^{-\rho t} \log c_{h t} d t\right]=\mathbb{E}^{\tilde{\mathbb{P}}}\left[\int_{0}^{+\infty} \mathcal{M}_{t} e^{-\rho t} \log c_{h t} d t\right]
$$

subject to the dynamic evolution of $\mathcal{M}_{t}$

$$
\frac{d \mathcal{M}_{t}}{\mathcal{M}_{t}}=-\frac{f_{t}}{\sigma_{d}} d Z_{d t}-\frac{\sqrt{n_{t}}}{\sigma_{e}} f_{t} d Z_{e t} ; \quad \mathcal{M}_{0}=1
$$

Finally, the evolution of the risky asset return under the specialists' beliefs can be represented as

$$
d R_{t}=\mu_{R t} d t+\sigma_{R d, t} d Z_{d t}+\sigma_{R e, t} d Z_{e t}=\left(r_{t}+\pi_{R t}\right) d t+\sigma_{R d, t} d Z_{d t}+\sigma_{R e, t} d Z_{e t}
$$

where the second equality replaces the expected return $\mu_{R t}$ with the sum of the instanta- 
neous risk-free rate $r_{t}$ and the risk premium $\pi_{R t}$ paid for holding the risky asset. Applying the change of measure from $\mathbb{P}$ to $\tilde{\mathbb{P}}$, under the households' beliefs, the risky asset return evolves as

$$
d R_{t}=\left(r_{t}+\pi_{R t}-\left(\frac{\sigma_{R d, t}}{\sigma_{d}}+\frac{\sigma_{R e, t} \sqrt{n_{t}}}{\sigma_{e}}\right) f_{t}\right) d t+\sigma_{R d, t} d \tilde{Z}_{d t}+\sigma_{R e, t} d \tilde{Z}_{e t} .
$$

Thus, the risk premium paid to the household for holding the risky asset is

$$
\pi_{R t}^{h}=\pi_{R t}-\left(\frac{\sigma_{R d, t}}{\sigma_{d}}+\frac{\sigma_{R e, t} \sqrt{n_{t}}}{\sigma_{e}}\right) f_{t} .
$$

When the households are more optimistic about expected dividend growth than the specialists, so that $f_{t}<0$, they are also more optimistic about the expected risky asset return as well. For a given level of disagreement $f_{t}$, households' expectations are affected more if the households exert more effort to acquire information (so that $\sqrt{n_{t}}$ is larger).

\subsection{State variables}

It is useful at this point to summarize the state variables in the economy and their evolutions under the specialist's information set. Since the specialist is the marginal investor in both the risky and the risk-free asset markets, asset prices satisfy his Euler equation and, hence, the specialist's information set is the relevant one in determining the time series behavior of returns. The full state vector in the economy is:

$$
\left(g_{t}, f_{t}, \gamma_{t}, y_{t}\right)
$$

Here, $y_{t}=w_{h t} / D_{t}$ is the relative wealth of the household. Since the households are constrained in their portfolio allocation decision, their relative wealth will be a driving factor for asset prices and, hence, the wealth evolutions in the economy. An alternative specification would be to have the current dividend $D_{t}$ as a state variable instead of $y_{t}$; 
however, this specification turns out to lead to more parsimonious asset pricing formulas. Parametrize the evolution of $y_{t}$ under the specialist's information set as:

$$
d y_{t}=\mu_{y t} d t+\sigma_{y d, t} Z_{d t}+\sigma_{y e, t} Z_{e t} .
$$

Notice that, in an economy with households only, $y_{t}$ corresponds to the inverse of the consumption-wealth ratio cay $y_{t}$ of Lettau and Ludvigson (2001), which has been shown to predict stock returns.

\subsection{Specialist's problem}

Since specialists are the only agents with access to the risky asset market, I assume that the specialists makes all of the investment decisions on the total capital of the intermediary and faces no portfolio restrictions in buying or short-selling either the risky asset or the risk-free bond. In particular, denote by $\alpha_{I t}$ the fraction of intermediary capital invested in the risky asset at time $t$ and by $w_{t}$ the specialist wealth at time $t$. Notice that, since all of the specialist's wealth is invested in the intermediary, $\alpha_{I t}$ is the effective exposure of the specialist to the risky asset. Then:

Proposition 2. The specialist chooses his consumption rate and the intermediary's exposure to the risky asset to solve:

$$
\max _{\left\{c_{t}, \alpha_{I t}\right\}} \mathbb{E}\left[\int_{0}^{+\infty} e^{-\rho t} \log c_{t} d t\right],
$$

subject to the specialist's budget constraint:

$$
d w_{t}=-c_{t} d t+w_{t} r_{t} d t+\alpha_{I t} w_{t}\left(d R_{t}-r_{t} d t\right) .
$$


The specialist's optimal consumption rule is:

$$
c_{t}=\rho w_{t}
$$

and the optimal risk exposure is:

$$
\alpha_{I t}=\frac{\pi_{R t}}{\sigma_{R d, t}^{2}+\sigma_{R e, t}^{2}} .
$$

Thus, the specialist consumes a fixed proportion, $\rho$, of his wealth each period, and invests according to the standard myopic investment rule.

\subsection{Household's problem}

Consider now the household's problem. Denote by $\alpha_{h t} \in[0,1]$ the fraction of household wealth allocated to the intermediary at time $t$. As in He and Krishnamurthy (2013), I assume that the household is precluded from shorting both the intermediary and the risk-free bond. Then the following result holds.

Proposition 3. Taking the specialist's wealth $w_{t}$ and exposure choice $\alpha_{I t}$ as given, the household solves:

$$
\max _{\left\{c_{h t}, \alpha_{h t}, h_{t}\right\}} \mathbb{E}\left[\int_{0}^{+\infty} e^{-\rho_{h} t} \log c_{h t} d t\right],
$$

subject to the household's budget constraint:

$$
d w_{h t}=-c_{h t} d t+w_{h t} r_{t} d t+\alpha_{h t} \alpha_{I t} w_{h t}\left(d R_{t}-r_{t} d t\right),
$$

the intermediation constraint:

$$
\alpha_{h t} w_{h t} \leq m w_{t}
$$


the no shorting constraint: $\alpha_{h t} \in[0,1]$ and the information processing constraint

$$
\gamma_{t}\left(\sigma_{d}^{-2}+\sigma_{e}^{-2} n_{t}\right) \leq \kappa
$$

The household optimally chooses to fully utilize its capacity to process information, so that

$$
n_{t}=\left(\frac{\kappa}{\gamma_{t}}-\sigma_{d}^{-2}\right) \sigma_{e}^{2}
$$

The household's optimal consumption rule is:

$$
c_{h t}=\rho_{h} w_{h t}
$$

and the optimal risk exposure in the unconstrained region is:

$$
\alpha_{h t}=\frac{\pi_{R t}-\left(\sigma_{d}^{-1} \sigma_{R d, t}+\sigma_{e}^{-1} \sigma_{R e, t} \sqrt{n_{t}}\right) f_{t}}{\alpha_{I t}\left(\sigma_{R d, t}^{2}+\sigma_{R e, t}^{2}\right)} .
$$

Thus, in the unconstrained region, the household also acts as a standard myopic investor, consuming a constant proportion of its wealth each period. As the precision of households' beliefs increases, the representative household can acquire a more precise external signal.

\subsection{Equilibrium}

Definition 2. An equilibrium in this economy is a set of price processes $\left\{P_{t}\right\}$ and $\left\{r_{t}\right\}$, and decisions $\left\{c_{t}, c_{h t}, \alpha_{I t}, \alpha_{h t}, n_{t}\right\}$ such that:

1. Given the price processes, decisions solve the consumption-savings problems of the specialist (2.8) and the household (2.11).

2. Decisions satisfy the intermediation constraint. 
3. The risky asset market clears:

$$
\alpha_{I t}\left(w_{t}+\alpha_{h t} w_{h t}\right)=P_{t}
$$

4. The goods market clears:

$$
c_{t}+c_{h t}=D_{t}
$$

Notice that, since the risk-free bonds are in equilibrium zero-net supply, the risky asset market clearing condition can be expressed as:

$$
w_{t}+w_{h t}=P_{t}
$$

\section{Asset prices}

In this section, I characterize the asset prices in the economy. Notice that, since the households are (potentially) constrained in making their investment decisions by the intermediation constraint, the specialist is the marginal agent in both the risky and the risk-free asset markets. In particular, the risk-free rate in the economy satisfies the Euler equation of the specialist but not necessarily that of the household.

\subsection{Risky asset price}

Begin by considering the risky asset price. Since the specialists and the households in this economy have log preferences, we can derive the risky asset price in closed form. Substituting the specialist's (2.9) and the household's (2.12) optimal consumption decisions into the goods market clearing condition (2.15), the price of the risky asset can be expressed 
as:

$$
P_{t}=w_{h t}\left(\frac{\rho-\rho_{h}}{\rho}\right)+\frac{1}{\rho} D_{t} .
$$

Thus, the equilibrium price-dividend ratio is given by:

$$
\frac{P_{t}}{D_{t}}=\frac{\rho-\rho_{h}}{\rho} y_{t}+\frac{1}{\rho}
$$

Recall that the economy is intermediation-constrained when the specialist has relatively low wealth, so that:

$$
\alpha_{h t}=\frac{\pi_{R t}-\left(\sigma_{d}^{-1} \sigma_{R d, t}+\sigma_{e}^{-1} \sigma_{R e, t} \sqrt{n_{t}}\right) f_{t}}{\alpha_{I t}\left(\sigma_{R d, t}^{2}+\sigma_{R e, t}^{2}\right)}>\frac{m w_{t}}{w_{h t}} .
$$

Rewriting, we obtain:

$$
y_{t} \geq \frac{m \pi_{R t}}{\rho\left[(1+m) \pi_{R t}-\left(\sigma_{d}^{-1} \sigma_{R d, t}+\sigma_{e}^{-1} \sigma_{R e, t} \sqrt{n_{t}}\right) f_{t}\right]} .
$$

Thus, the $y$ boundary of the intermediation-constrained region is increasing in the Sharpe ratio and decreasing in the disagreement between the specialist and the household. Figure 1 plots the boundary between the unconstrained and the constrained regions as a function of the disagreement between the specialist and the household $f$ ( $y$ axis) and the scaled wealth of the household $y$ ( $x$ axis). As households become more wealthy as a share of total output in the economy, the constraint boundary decreases, making it more likely that the economy will be intermediation-constrained. Intuitively, as the relative wealth of households increases, the relative wealth of specialists must decrease, making the intermediation constraint tighter. Similarly, as the household becomes more optimistic relative to the specialist, so that $f_{t}$ decreases, the constraint boundary decreases, making it more likely that the economy will be intermediation-constrained. Intuitively, as households 
become more optimistic about the expected dividend growth rate, the optimal share of their wealth allocated to the intermediary increases, making the intermediation constraint tighter. For the parameters of the dividend growth process, the long-run mean of the dividend growth process, and the external signal, I adapt the calibration of Bansal and Yaron (2004) for my specification. The capacity of the specialist to process information, $\kappa$, is chosen to make the initial information choice 0 :

$$
\kappa=\frac{1}{2} \frac{\gamma_{0}}{\sigma_{d}^{2}}
$$

and the prior variance of the household's $\left(\gamma_{0}\right)$ belief are chosen to be 1 . As in He and Krishnamurthy $(2013,2012)$, I choose the maximal leverage of the specialists, $m$, to be 4 . As discussed in He and Krishnamurthy (2013), the choice of $m$ corresponds to the equity capital constraints of banks and hedge funds, since these institutions are more likely to be the marginal buyers of risky assets during periods when equity capital is constrained. Finally, the time discount rate in the economy is chosen to be $1 \%$. The parameters used for this numerical illustration are summarized in Table 1.

Applying Ito's lemma to the price-dividend ratio, the risky asset return becomes

$$
\begin{aligned}
d R_{t} & =\frac{\rho}{y_{t}\left(\rho-\rho_{h}\right)+1} d t+\frac{d D_{t}}{D_{t}}+\frac{y_{t}\left(\rho-\rho_{h}\right)}{y_{t}\left(\rho-\rho_{h}\right)+1} \frac{d y_{t}}{y_{t}}+\frac{y_{t}\left(\rho-\rho_{h}\right)}{y_{t}\left(\rho-\rho_{h}\right)+1}\left\langle\frac{d y_{t}}{y_{t}}, \frac{d D_{t}}{D_{t}}\right\rangle \\
& =\left(\frac{\rho}{y_{t}\left(\rho-\rho_{h}\right)+1}+g_{t}+\frac{y_{t}\left(\rho-\rho_{h}\right)}{y_{t}\left(\rho-\rho_{h}\right)+1}\left(r_{t}-\rho_{h}+\alpha_{h t} \alpha_{I t} \pi_{R t}-g_{t}\right)\right) d t \\
& +\frac{\sigma_{d}}{1+y_{t}\left(\rho-\rho_{h}\right)\left(1-\alpha_{h t} \alpha_{I t}\right)} d Z_{d t} .
\end{aligned}
$$

Thus, the households' news shock $d Z_{e t}$ does not impact returns directly, and only enters through its impact on the households' beliefs and their portfolio choice $\alpha_{h t}$. 


\subsubsection{Return volatility}

Substituting the intermediaries' optimal portfolio choice into the risky asset returns process (3.1), we obtain the following result.

Proposition 4. The equilibrium risky asset return volatility satisfies:

$$
\sigma_{R d, t}=\frac{\sigma_{d}}{1+\left(\rho-\rho_{h}\right) y_{t}}+\frac{y_{t}\left(\rho-\rho_{h}\right)}{1+\left(\rho-\rho_{h}\right) y_{t}} \alpha_{h t} \frac{\pi_{R t}}{\sigma_{R d, t}} .
$$

Thus, in the intermediation-unconstrained region, the risky asset return volatility is given by:

$$
\sigma_{R d, t}=\frac{\sigma_{d}}{1+\left(\rho-\rho_{h}\right) y_{t}}+\frac{y_{t}\left(\rho-\rho_{h}\right)}{1+\left(\rho-\rho_{h}\right) y_{t}}\left(\frac{\pi_{R t}}{\sigma_{R d, t}}-\frac{f_{t}}{\sigma_{d}}\right) .
$$

When the economy is in the intermediation-constrained region, the risky asset return volatility becomes:

$$
\sigma_{R d, t}=\frac{\sigma_{d}}{1+\left(\rho-\rho_{h}\right) y_{t}}+\frac{m\left(\rho-\rho_{h}\right)\left(1-\rho_{h} y_{t}\right)}{1+\left(\rho-\rho_{h}\right) y_{t}} \frac{\pi_{R t}}{\sigma_{R d, t}} .
$$

Notice that, in the intermediation-constrained region, the risky asset return volatility does not depend on the disagreement between the specialist and the household while the disagreement does influence the volatility in the unconstrained region. Intuitively, in the intermediation-constrained region, the households are constrained in choosing their portfolio allocation, and are thus the inframarginal investors in the risky asset. Thus, the price of the risky asset in the constrained region reflects only the beliefs of the specialist. In the unconstrained region, both the specialist and the household are at their unconstrained optimum, so the risky asset price balances both of their beliefs. Notice also that, unlike the perfect information setting of He and Krishnamurthy (2012), the disagreement between the specialist and the household and the learning process of the specialist introduce stochastic volatility in the returns process even in the unconstrained region. The 
volatility of the returns process is increasing in the Sharpe ratio of the risky asset, both in the constrained and the unconstrained region of the economy. Notice also that, asymptotically, as $y_{t} \rightarrow+\infty$, which corresponds to the economy becoming increasingly more intermediation-constrained, $\sigma_{R d, t}^{2} \rightarrow-m \rho_{h} \pi_{R t}$. Intuitively, as the household becomes infinitely large relative to the economy, asset prices converge to the shadow asset prices in an economy where the household is the only agent in the economy, but cannot trade in the risky asset. At the other extreme, as $y_{t} \rightarrow 0$, so that the economy becomes increasingly less intermediation-constrained, $\sigma_{R d, t} \rightarrow \sigma_{d}$. Thus, as the specialist becomes the dominant agent in the economy, the risky asset volatility depends only on the fluctuation in dividend growth.

The top right panel of Figure 2 plots the return volatility as a function of the relative household wealth, and the disagreement between the households and intermediaries. As the relative household wealth increases, the return volatility increases since the same quantity of risky assets have to be distributed across a smaller amount of specialist wealth. As the disagreement between specialists and households increases, the return volatility decreases. To understand this effect, consider the relationship between disagreement and the fraction of household wealth allocated to the intermediary, plotted in the bottom left panel of Figure 3. When disagreement is high, households allocate a smaller fraction of their wealth to the intermediary. Thus, there is less trade between households and specialists, reducing return volatility. This is similar to the intuition of Scheinkman and Xiong (2003), who show that return volatility increases when there is more trade in the risky asset, since the volatility of the resale option increases with more trade.

\subsubsection{Risk premium}

Turn now to the equilibrium risk premium. Substituting the optimal portfolio choice of the intermediaries into the expected return expression from (3.1), we obtain the following result. 
Proposition 5. The equilibrium risk premium satisfies:

$$
\pi_{R t}=\frac{g_{t}-r_{t}-\rho_{h}\left(\rho-\rho_{h}\right) y_{t}}{1+\left(\rho-\rho_{h}\right) y_{t}}\left(1+y_{t}\left(\rho-\rho_{h}\right) \alpha_{h t} \frac{\pi_{R t}}{\sigma_{R d, t}} \sigma_{d}^{-1}\right)
$$

Thus, in the intermediation-unconstrained region, the risk premium is given by:

$$
\pi_{R t}=\frac{g_{t}-r_{t}-\rho_{h}\left(\rho-\rho_{h}\right) y_{t}}{1+\left(\rho-\rho_{h}\right) y_{t}}\left(1+y_{t}\left(\rho-\rho_{h}\right)\left(\frac{\pi_{R t}}{\sigma_{R d, t}}-\frac{f_{t}}{\sigma_{d}}\right) \sigma_{d}^{-1}\right) .
$$

When the economy is in the intermediation-constrained region, the risk premium becomes:

$$
\pi_{R t}=\frac{g_{t}-r_{t}-\rho_{h}\left(\rho-\rho_{h}\right) y_{t}}{1+\left(\rho-\rho_{h}\right) y_{t}}\left(1+m\left(\rho-\rho_{h}\right)\left(1-\rho_{h} y_{t}\right) \frac{\pi_{R t}}{\sigma_{R d, t}} \sigma_{d}^{-1}\right)
$$

Similarly to the risky asset return volatility, in the intermediation-constrained region, the risk premium does not depend on the disagreement between the specialist and the household while the disagreement does influence the risk premium in the unconstrained region. Asymptotically, as $y_{t} \rightarrow+\infty$, the risk premium becomes:

$$
\lim _{y_{t} \rightarrow+\infty} \pi_{R t}=+\infty
$$

Intuitively, in the economy where the households are the only agents, no agent can hold the risky asset, leading to an infinite risk premium. At the other extreme, as $y_{t} \rightarrow 0$, the equilibrium risk premium converges to:

$$
\lim _{y_{t} \rightarrow 0} \pi_{R t}=\sigma_{d}^{2}-\rho
$$

As with the risky asset return volatility, as the specialist becomes the dominant agent in the economy, the equilibrium risk premium is converges to the one that would arise in a economy with only specialists.

The top left panel of Figure 2 plots the risk premium as a function of the relative 
household wealth and the disagreement between the households and intermediaries. As the relative wealth of the households increases, the risky asset has to be held by a smaller mass of specialists, increasing the required risk premium. This effect becomes more pronounced in the intermediation-constrained region, since the specialists cannot fully supplement their own funds with household contributions in clearing the risky asset market, driving the risk premium up. Notice, however, that the increases in the risk premium are not perfectly off-set by the increase in the risky asset volatility: the Sharpe ratio of the risky asset (bottom left panel of Figure 2) is also increasing in the scaled wealth of the household. Further, as the disagreement between the households and intermediaries increases, the risk premium increases as well, since the more pessimistic households have to be compensated for holding the risky asset more. This, combined with the negative relationship between return volatility and disagreement, implies that the Sharpe ratio of the risky asset is also increasing in the disagreement between households and specialists.

\subsection{Risk-free rate}

Since the specialist is the marginal investor in the risk-free market, the risk-free rate satisfies the specialist's Euler equation:

$$
r_{t} d t=\rho d t+\mathbb{E}\left[\frac{d w_{t}}{w_{t}} \mid \mathcal{F}_{t}\right]-\operatorname{var}\left(\frac{d w_{t}}{w_{t}} \mid \mathcal{F}_{t}\right)
$$

Using the goods market clearing condition, intermediary wealth evolves as

$$
\frac{d w_{t}}{w_{t}}=\frac{d\left(D_{t}-\rho_{h} w_{h t}\right)}{D_{t}-\rho_{h} w_{h t}}=\frac{d D_{t} / D_{t}-\rho_{h} y_{t} d w_{h t} / w_{h t}}{1-\rho_{h} y_{t}}
$$

This yields the following result. 
Proposition 6. The equilibrium risk-free rate is given by:

$$
r_{t}-\rho-g_{t}=-\rho_{h}\left(\rho-\rho_{h}\right) y_{t}-\rho_{h} y_{t} \alpha_{h t} \alpha_{I t} \pi_{R t}-\frac{\left(\sigma_{d}-\rho_{h} y_{t} \alpha_{h t} \alpha_{I t} \sigma_{R d, t}\right)^{2}}{1-\rho_{h} y_{t}}
$$

Thus, in the intermediation-unconstrained region, the risk-free rate is given by:

$r_{t}-\rho-g_{t}=-\rho_{h}\left(\rho-\rho_{h}\right) y_{t}-\rho_{h} y_{t}\left(\frac{\pi_{R t}}{\sigma_{R d, t}}-\frac{f_{t}}{\sigma_{d}}\right) \frac{\pi_{R t}}{\sigma_{R d, t}}-\frac{1}{1-\rho_{h} y_{t}}\left(\sigma_{d}-\rho_{h} y_{t}\left(\frac{\pi_{R t}}{\sigma_{R d, t}}-\frac{f_{t}}{\sigma_{d}}\right)\right)^{2}$.

When the economy is in the intermediation-constrained region, the risk-free rate becomes:

$r_{t}-\rho-g_{t}=-\rho_{h}\left(\rho-\rho_{h}\right) y_{t}-m \rho_{h}\left(1-\rho_{h} y_{t}\right) \frac{\pi_{R t}^{2}}{\sigma_{R d, t}^{2}}-\frac{1}{1-\rho_{h} y_{t}}\left(\sigma_{d}-m \frac{\pi_{R t}}{\sigma_{R d, t}}\left(1-\rho_{h} y_{t}\right)\right)^{2}$.

Thus, the risk-free rate is increasing in the expected long-run dividend growth rate and decreasing in the Sharpe ratio in both the constrained and the unconstrained regions of the economy. Asymptotically, as $y_{t} \rightarrow+\infty$, the risk-free rate becomes:

$$
\lim _{y_{t} \rightarrow+\infty} r_{t}=-\infty
$$

Intuitively, as the household becomes the dominant agent in the economy, the demand for borrowing by the specialist decreases, while the supply of credit by the households increases, driving the equilibrium interest rate to $-\infty$. At the other extreme, as $y_{t} \rightarrow 0$, the equilibrium risk-free rate converges to:

$$
\lim _{y_{t} \rightarrow 0} r_{t}=\rho+g_{t}-\sigma_{d}^{2}
$$

Thus, as the specialist becomes the dominant agent in the economy, the risk-free rate is determined by his beliefs about the long-run expected dividend growth rate.

The bottom right panel of Figure 2 plots the equilibrium risk-free rate in the economy as a function of the relative household wealth and the disagreement between the house- 
holds and intermediaries (y-axis). As the specialist becomes more optimistic relative to the household, the risk-free rate decreases. Intuitively, as the specialist becomes more optimistic, the household is less willing to invest in the risky asset and, hence, more willing to invest in the risk-free asset, lowering the interest rate. The risk-free rate also decreases as the household becomes more dominant in the economy. Thus, as the scaled household wealth increases, the lending demand by specialists is distributed across a larger mass of households, lowering the risk-free rate. Notice that this is the risk-free asset market counterpart to the mechanism that increases the risk premium (and the Sharpe ratio) as specialists become less dominant in the economy. Since the asset markets must clear in equilibrium, the relative size of the natural owners of the two types of assets (households for the risk-free asset and specialists for the risky asset) impacts the level of the expected return in the corresponding markets.

\subsection{Portfolio allocations}

Turn now to the relationship between the optimal portfolio allocation choices of the households and the intermediaries and the state variables in the economy. The right panel of Figure 3 plots the percentage of intermediary capital allocated to the risky asset $\left(\alpha_{I t}\right)$ and the left panel plots the percentage of household wealth allocated to the intermediary $\left(\alpha_{h t}\right)$ as a function of the relative household wealth ( $x$-axis) and the disagreement between the households and intermediaries ( $y$-axis). Notice first, that as the specialists become more optimistic relative to the households (so that $f$ becomes more positive), $\alpha_{I}$ increases and $\alpha_{h}$ increases. Intuitively, as the specialists become more optimistic, they are willing to invest more in the risky asset while the opposite holds true for the households. In particular, when the specialists and the households agree on the expected dividend growth rate (so that $f=0$ ) or when the specialists are pessimistic relative to the households (so that $f<0$ ), the no shorting constraint begins to bind for the households, constraining their allocation to the intermediary to only be as large as their wealth. At the other ex- 
treme, when the household becomes extremely pessimistic relative to the intermediary, the household faces the constraint that it cannot short the intermediary and is forced to put all its wealth in the risk-free asset.

When the specialist is more optimistic than the household, as the relative importance of the household in the economy increases, the household's allocation into the intermediary increases, until the economy enters into the intermediation-constrained region. Intuitively, as the household becomes a larger fraction of the economy, asset prices are increasingly more reflective of the household's belief, in addition to that of the specialist, making households more likely to invest in the risky asset. This effect also accounts for the opposite behavior of the specialist's portfolio choice: for large optimism on the part of the specialist, the fraction of intermediary capital allocated to the intermediary increases as the scaled wealth of the household increases while the household is constrained to invest 0 , but decreases when the household is finally able to enter the market. When the beliefs of the specialist and the household are more in sync, the fraction of intermediary capital allocated to the risky asset increases for some range out the household's scaled wealth in the region where the household is not constrained, but decreases for larger values of $y$.

\subsection{Stationary Distribution}

In this Section, I examine the stationary distribution of the variables in the economy. First, notice that in the stationary equilibrium, the stationary variance $\bar{\gamma}$ of the households' beliefs solves

$$
0=\frac{\partial \gamma_{t}}{\partial t}=-2 \kappa_{g} \bar{\gamma}+\sigma_{g}^{2}-2 \kappa \bar{\gamma}
$$

so that the stationary variance is

$$
\bar{\gamma}=\frac{1}{2}\left(\kappa_{g}+\kappa\right)^{-1} \sigma_{g}^{2}
$$


There are two notable differences between the stationary precision of beliefs for an agent with limited attention and those for an agent that learns from a signal with a given precision. First, for the rationally inattentive agent, the speed of decrease (over time) of the variance of beliefs is linear in $\gamma_{t}$. For the agent learning from signals with fixed precision, on the other hand, the speed of decrease is a quadratic function of $\gamma_{t}$. This implies that, while initially (while $\gamma$ is large) the rationally inattentive agent learns slower, in the long run speed of convergence to the stationary level of $\gamma$ is larger than that of the agent who learns from fixed precision signals. Second, the variance of beliefs need not converge to the sample level for the two agents. In particular, for the rationally inattentive agent, the stationary signal precision is

$$
\frac{\bar{n}}{\sigma_{e}^{2}}=2 \frac{\kappa}{\bar{\gamma}}-\sigma_{d}^{-2}=4 \kappa\left(\kappa_{g}+\kappa\right) \sigma_{g}^{-2}-\sigma_{d}^{-2}
$$

The stationary variance of beliefs $\tilde{\gamma}$ of an agent that learns from the signal with that fixed precision, on the other hand, solves

$$
0=-2 \kappa_{g} \tilde{\gamma}+\sigma_{g}^{2}-4 \tilde{\gamma}^{2} \kappa\left(\kappa_{g}+\kappa\right) \sigma_{g}^{-2},
$$

so that

$$
\tilde{\gamma}=\frac{-\kappa_{g}+\sqrt{\kappa_{g}^{2}+4 \kappa\left(\kappa_{g}+\kappa\right)}}{4 \kappa\left(\kappa_{g}+\kappa\right)} .
$$

Using the stationary variance of households' beliefs, disagreement evolves as

$$
d f_{t}=-\left(\kappa_{g}+2 \kappa\right) f_{t} d t+\sigma_{d} d Z_{g t}-\frac{\bar{\gamma}}{\sigma_{d}} d Z_{d t}-\bar{\gamma} \sqrt{\frac{2 \kappa}{\bar{\gamma}}-\frac{1}{\sigma_{d}^{2}}} d Z_{e t}
$$

Since the variance of households' beliefs does not converge to 0 in the stationary equilibrium, disagreement between households and specialists does not converge to 0 as well. 
Thus, the stationary equilibrium of this economy is described by three state variables: the expected growth rate of dividends $g_{t}$, the disagreement between households and specialists $f_{t}$ and the household wealth as a fraction of dividends $y_{t}$. Denote by $\varphi(g, f, y)$ the joint stationary distribution of the state variables. The joint distribution satisfies the Fokker-Planck equation with the time derivative set to 0

$$
\begin{aligned}
0 & =\kappa_{g} \varphi-\kappa_{g}(\bar{g}-g) \frac{\partial \varphi}{\partial g}+\left(\kappa_{g}+2 \kappa\right) \varphi+\left(\kappa_{g}+2 \kappa\right) f \frac{\partial \varphi}{\partial f}-\frac{\partial \mu_{y t}}{\partial y} \varphi-\mu_{y t} \frac{\partial \varphi}{\partial y} \\
& +\frac{\sigma_{g}^{2}}{2} \frac{\partial^{2} \varphi}{\partial g^{2}}+\frac{\sigma_{g}^{2}+\bar{\gamma} \kappa}{2} \frac{\partial^{2} \varphi}{\partial f^{2}}+\sigma_{g}^{2} \frac{\partial^{2} \varphi}{\partial g \partial f}+\frac{1}{2} \frac{\partial^{2} \sigma_{y d, t}}{\partial y^{2}} \varphi+\frac{\sigma_{y d, t}^{2}}{2} \frac{\partial^{2} \varphi}{\partial y^{2}}+\frac{\partial \sigma_{y d, t}^{2}}{\partial y} \frac{\partial \varphi}{\partial y} \\
& -\frac{\bar{\gamma}}{\sigma_{d}} \frac{\partial^{2} \sigma_{y d, t}}{\partial f \partial y} \varphi-\frac{\bar{\gamma}}{\sigma_{d}} \frac{\partial \sigma_{y d, t}}{\partial f} \frac{\partial \varphi}{\partial y}-\frac{\bar{\gamma}}{\sigma_{d}} \frac{\partial \sigma_{y d, t}}{\partial y} \frac{\partial \varphi}{\partial f}-\frac{\bar{\gamma}}{\sigma_{d}} \sigma_{y d, t} \frac{\partial^{2} \varphi}{\partial f \partial y^{\prime}}
\end{aligned}
$$

subject to the boundary conditions

$$
\lim _{y \rightarrow 0} \varphi=0 ; \quad \lim _{y \rightarrow+\infty} \varphi=0 ; \quad \lim _{g \rightarrow \pm \infty} \varphi=0 ; \quad \lim _{f \rightarrow \pm \infty} \varphi=0 ; \quad \int \varphi d y d f d g=1 .
$$

This is a non-linear partial differential equation in three variables, which requires a numerical solution. I solve for the stationary distribution using a variation of the Method of Lines; the details of the procedure are described in Appendix B.

Figure 4 plots bivariate marginal stationary densities. Panel (a) shows that most of the density is concentrated in the region of low disagreement and intermediate levels of household wealth. Thus, even in the stationary equilibrium of the economy, the intermediation constraint binds for a relevant fraction of economic realizations. The univariate marginal of household wealth, plotted in Panel (a) of Figure 5, in fact has a bimodal distribution, with one peak to the left of the intermediation constraint (where the constraint does not bind) and one peak to the right (where the constraint does bind). It is important to also note that the stationary distribution is not degenerate in household wealth; thus, both specialists and households do in fact survive in the stationary equilibrium of the economy. The mechanism for survival is, however, different than that usually con- 
sidered in the heterogeneous preferences literature (see e.g. Borovička, 2013). Here, the survival of both types of agents occurs not due to utility function heterogeneity or timeinseparability, but rather because of heterogeneous access to asset markets. As the households grow in the economy, the intermediation constraint limits their allocation into the risky asset markets, dampening their growth relative to the growth of the specialists. As the wealth of the specialists increases, the households are able to contribute more to the intermediary, and receive a larger share of the profits of the intermediary.

Turning to Panel (b) of Figure 4, we see that the joint density of household wealth and expected dividend growth has a similar shape, albeit this density is centered around $\bar{g}$ (and not 0 , as is the case for disagreement) along the expected dividend growth dimension. This is not surprising: in the stationary equilibrium, innovations to expected dividend growth and disagreement have correlation close to 1. Indeed, in Panel (c) we can see that joint density of expected growth and disagreement is almost perfectly symmetric. Panel (b) and (c) of Figure 5 confirm, respectively, that disagreement is centered around 0 and expected dividend growth around $\bar{g}$.

Panel (d) of Figure 4 plots the joint density of the equilibrium risk premium paid to investors in the risky asset and the equilibrium volatility of the risky asset return. Most of the density is concentrated at higher levels of volatility and lower levels of the equity risk premium, leading to a relatively tight distribution of the Sharpe ratio (Panel (d) of Figure 5). Although the risk premium in the stationary equilibrium is lower than that observed empirically (1.5-2.7\% in the model versus $6-8 \%$ in the data), it is much higher than the one that would arise in a model with a representative agent with log preferences.

\section{Empirical Analysis}

In this Section, I conduct simple exploratory empirical analysis to examine the testable predictions of the model. The model predicts that: 
1. Higher household wealth increases expected returns and decreases return volatility.

2. Higher disagreement increases expected returns and decreases return volatility while the households are unconstrained and does not impact either expected returns or return volatility when the households become constrained.

The empirical evidence is consistent with these predictions, although the degree of statistical significance varies across specifications.

\subsection{Data}

In the empirical analysis, I interpret the disagreement between specialists and households broadly and focus on variation in the disagreement about the overall future prospects of the economy. I use the disagreement over quarter-over-quarter change in nominal GDP from the Survey of Professional Forecasters, obtained from the Federal Reserve Bank of San Francisco. Disagreement is measured as the interquartile range across the survey respondents, which I scale by the median forecast to make the measure comparable over time. Figure 6 plots the quarterly observations of the disagreement over current quarter nominal GDP growth. The disagreement decreases during booms, and increases during recessions. As a robustness check, the regressions below also use disagreement over the next quarter nominal GDP growth as an alternative measure of disagreement, as well as disagreement over the price level in GDP and real GDP.

I use two different measures of the relative wealth of the households in the economy: the total financial assets held by households and the total value of mutual funds shares held by households, obtained from Flow of Funds Table L.100. While the total financial assets held by households measures the financial wealth of the household sector in the United States, the total value of mutual fund shares proxies for household wealth intermediated through the mutual fund industry. I detrend both series by constructing four quarter changes. Figure 6 plots the quarterly observations of the annual growth rate of the 
total financial assets held by the households over time. The asset growth rate decreases and becomes negative during recessions, and increases during booms.

\subsection{Equity risk premium}

I begin by testing the relationship between the equity risk premium, household wealth, and disagreement. The model predicts that the risk premium is increasing in household wealth (since the same amount of risk has to be borne by a smaller amount of specialist wealth), and, while the households are unconstrained, increasing in disagreement between households and specialists. Indeed, the top panel of Figure 7 shows a positive association between realized returns on the S\&P 500 and household financial wealth, and the bottom panel a positive association between realized returns and disagreement over the current quarter nominal GDP growth. The relationship between realized excess returns and household wealth is especially strong during recessions.

To assess the significance of these relationships and to test that they hold for expected as well as realized returns, I estimate

$$
R_{t, t+1}=\alpha+\beta_{E} \Delta E_{t}+\beta_{D} D_{t}+\beta_{R} D_{t} \times \mathbf{1}_{\text {Recession }}+\epsilon_{t+1}
$$

where $\Delta E_{t}$ is the growth rate of household wealth between quarter $t-1$ and $t, D_{t}$ is the disagreement in quarter $t$ and $D_{t} \times \mathbf{1}_{\text {Recession }}$ is the interaction between disagreement in quarter $t$ and the NBER recession indicator in quarter $t$. As proxy for the equity risk premium in quarter $r$, I use realized future excess market returns $R_{t, t+1}$, constructed as the continuously compounded return on the S\&P 500 between quarter $t$ and $t+1 / 3$ in excess of the continuously compounded Federal Funds rate. Table 2 reports the coefficients and the Newey-West standard errors with four quarter truncation from the above regression using different proxies for the relative household wealth in the economy and the disagreement between households and specialists. Panels A and B use the total financial 
asset holdings of the households, and Panels $C$ and D the mutual fund share holdings as proxies for household wealth. Panels $A$ and $C$ use the interquartile range of forecasts, scaled by the median forecast, for current quarter GDP growth measures (nominal, price level and real) as a proxy for disagreement, while Panels B and D use the interquartile range of forecasts, scaled by the median forecast, for next quarter GDP growth measures. In all specifications, consistent with the time series plots of Figure 7, increases in household wealth lead to increases in the risk premium. The model predictions for the relationship between risk premium and disagreement are also borne out in most specifications. During normal periods, increases in disagreement lead to increases in the risk premium. In recessions, household participation in the risky asset markets, reducing the impact of household beliefs and, hence disagreement, on the risk premium.

\subsection{Stock market volatility}

According to the model, when households are more impatient than the specialists, stocks should be more volatile when households represent a higher fraction of wealth in the economy, and when the disagreement between households and specialists is lower. I use two measures of return volatility: realized volatility measured as the standard deviation of daily returns over the preceding month, and implied volatility measured by the CBOE Volatiity Index (VIX). The top panel of Figure 8 reveals a negative association between volatility and household financial wealth, and the bottom panel a positive association between volatility and disagreement during recessions. To assess the significance of these relationships and to test whether the impact of disagreement is diminished when specialist wealth is depleted, I estimate

$$
V_{t}=\alpha+\beta_{V} V_{t-1}+\beta_{E} \Delta E_{t}+\beta_{D} D_{t}+\beta_{R} D_{t} \times \mathbf{1}_{\text {Recession }}+\epsilon_{t},
$$


where $V_{t}$ is volatility (either the realized volatility $R V_{t}$ or the implied volatility $I V_{t}$ ) at date $t$ and, as before, $\Delta E_{t}$ is the growth rate of household wealth between quarter $t-1$ and $t, D_{t}$ is the disagreement in quarter $t$ and $D_{t} \times \mathbf{1}_{\text {Recession }}$ is the interaction between disagreement in quarter $t$ and the NBER recession indicator in quarter $t$.

Table 3 reports the estimated coefficients from a quarterly regression of the realized volatility, together with Newey-West standard errors with four quarter truncation, using the same proxies for household wealth (total financial asset holdings and mutual fund share holdings) and disagreement as above. Notice that including lagged volatility removes most of the serial correlation in the residuals. Consistent with the model predictions, increases in household wealth lead to decreases in volatility in all regression specifications. The model's predictions for the relationship between volatility and disagreement are also borne out in the specifications using either nominal or real GDP. During normal periods, increases in disagreement lead to decreases in volatility. During recessions, changes in disagreement have little impact on return volatility since households disinvest from intermediaries, reducing the impact of household beliefs on asset prices. Table 4 confirms that these predictions also hold when implied volatility is used as the proxy for return volatility instead of realized volatility.

\section{Conclusion}

I present a dynamic model of intermediation and information acquisition. The disparity in information between specialists and households introduces endogenous disagreement between the two types of agents in the economy. Although households decrease the information gap by observing additional signals, their limited capacity to process information prevents them from becoming as informed as the specialists. This changes the shape of the intermediation-constrained region of the economy, and increases the frequency of periods when the intermediation constraint binds. 
When the intermediation constraint is lax, higher disagreement between households and specialists increases the equity risk premium and decreases the return volatility. In the constrained region of the economy, since the households are constrained in their portfolio allocation, disagreement does not impact the equilibrium asset pricing moments. I find empirical evidence consistent with these predictions, as well as the prediction that higher household wealth increases risk premia and decreases return volatility. 


\section{References}

Allen, F., Gale, D., 1994. Limited market participation and volatility of asset prices. American Economic Review 84, 933-955.

Bansal, R., Yaron, A., 2004. Risks for the Long-Run: A Potential Resolution of Asset Pricing Puzzles. Journal of Finance 59, 1481-1509.

Basak, S., Cuoco, D., 1998. An Equilibrium Model with Restricted Stock Market Participation. Review of Financial Studies 11, 309-341.

Borovička, J., 2013. Survival and Long-Run Dynamics with Heterogeneous Beliefs under Recursive Preferences. Working paper, New York University.

Boyarchenko, N., Duarte, F., 2012. Investing in capacity: Long-run effects of rational inattention, unpublished working paper, Federal Reserve Bank of New York.

Brunnermeier, M. K., Sannikov, Y., 2013. A Macroeconomic Model with a Financial Sector. American Economic Review.

Collin-Dufresne, P., Johannes, M., Lochstoer, L. A., 2013. Parameter Learning in General Equilibrium: The Asset Pricing Implications. Working paper 19705, National Bureau of Economic Research.

Cox, J., Huang, C., 1989. Optimal Consumption and Portfolio Policies when Asset Prices follow a Diffusion Process. Journal of Economic Theory 49, 33-83.

Cvitanić, J., Karatzas, I., 1992. Convex Duality in Constrained Portfolio Optimization. The Annals of Applied Probability 2 (4), 767-818.

Detemple, J. B., Kihlstrom, R. E., 1987. Acquisition d'information dans un modèle intertemporel en temps continu. L'Actualité Économique. Revue d'analyse économique $63,118-137$.

Diamond, D. W., Dybvig, P. H., 1983. Bank runs, deposit insurance and liquidity. Journal of Political Economy 93 (1), 401-419.

Diamond, D. W., Rajan, R., 2005. Liquidity shortages and banking crises. Journal of Finance 60, 2177-2207.

Haddad, V., 2012. Concentrated Ownership and Asset Prices, unpublished working paper, Princeton University.

He, Z., Krishnamurthy, A., 2012. A Model of Capital and Crises. Review of Economic Studies 79 (2), 735-777.

He, Z., Krishnamurthy, A., 2013. Intermediary Asset Pricing. American Economic Review $103(2), 732-770$. 
Holmstrom, B., Tirole, J., 1997. Financial intermediation, loanable funds, and the real sector. Quarterly Journal of Economics 112 (3), 663-691.

Hong, H., Torous, W., Valkanov, R., 2007. Do industries lead stock markets? Journal of Financial Economics 83, 367-396.

Huang, L., Liu, H., 2007. Rational Inattention and Portfolio Selection. Journal of Finance LXII (4), 1999-2040.

Kacperczyk, M., van Nieuwerburgh, S., Veldkamp, L., 2011. Attention allocation over the business cycle: Evidence from the mutual fund industry, unpublished working paper.

Lettau, M., Ludvigson, S., 2001. Consumption, aggregate wealth and expected stock returns. Journal of Finance 56, 815-849.

Liptser, R. S., Shiryaev, A. N., 1977. Statistics of Random Processes: I,II. Springer-Verlag, New York.

Lucas, R. E., 1978. Asset prices in an exchange economy. Econometrica 46, 1429-1446.

Mankiw, N. G., Zeldes, S. P., 1991. The consumption of stockholders and non-stockholdes. Journal of Financial Economics 29, 97-112.

van Nieuwerburgh, S., Veldkamp, L., 2010. Information acquisition and underdiversification. Review of Economic Studies 77(2), 779-805.

Scheinkman, J. A., Xiong, W., 2003. Overconfidence and speculative bubbles. Journal of Political Economy 111 (6), 1183-1220.

Sims, C., 2003. Implications of rational inattention. Journal of Monetary Economics 50, 665-690.

Sims, C., 2006. Rational inattention: Beyond the linear quadratic case. The American Economic Review 96 (2), 158-163.

Turmuhambetova, G. A., 2005. Decision making in an economy with endogenous information. Ph.D. thesis, University of Chicago, Department of Economics.

Vissing-Jorgensen, A., 2002. Limited asset market participation and the elasticity of intertemporal substitution. Journal of Political Economy 110, 825-853. 


\section{A Proofs}

\section{A.1 Proof of Proposition 2}

Denote by $J$ the value function of the specialist at time $t$ :

$$
J\left(w_{t}, g_{t}, \gamma_{t}, f_{t}, y_{t}\right)=\max _{\left\{c_{s}, \alpha_{I s}\right\}} \mathbb{E}\left[\int_{t}^{+\infty} e^{-\rho s} \log c_{s} d s\right],
$$

subject to the dynamic budget constraint

$$
d w_{t}=-c_{t} d t+w_{t} r_{t} d t+\alpha_{I t} w_{t}\left(\pi_{R t} d t+\sigma_{R d, t} d Z_{d t}+\sigma_{R e, t} d Z_{e t}\right)
$$

Instead of solving the dynamic optimization problem, I follow Cvitanić and Karatzas (1992) and rewrite the fund manager problem in terms of a static optimization. Cvitanić and Karatzas (1992) extend the Cox and Huang (1989) martingale method approach to constrained optimization problems, such as the one that the fund managers face in our economy. Notice that, even though the specialists do not face no-shorting constraints, the market is incomplete from their point of view since there are three shocks in the economy, $d Z_{d t}, d Z_{g t}$ and $d Z_{e t}$, but only one risky asset. Introduce $\alpha_{g t}$ to be the fraction of fund equity allocated to claims to $d Z_{g t}, \alpha_{e t}$ be the fraction of fund equity allocated to claims to $d Z_{e t}$, and let $\vec{\alpha}_{f t} \equiv\left[\alpha_{I t} \alpha_{e t} \alpha_{g t}\right]^{\prime}$ be the vector of portfolio choices of the fund at time $t$.

Define $\mathcal{K}=\left\{\pi \in \mathbb{R}^{3}: \pi_{1}=\pi_{2} ; \pi_{3}=0\right\}$ to be the convex set of admissible portfolio strategies and introduce the support function of the set $-\mathcal{K}$ to be

$$
\begin{aligned}
\delta(x) & =\delta(x \mid \mathcal{K}) \equiv \sup _{\overrightarrow{\alpha_{f}} \in \mathcal{K}}\left(-\vec{\alpha}_{f}^{\prime} x\right) \\
& = \begin{cases}0, & \text { if } x_{1}=-x_{2} \\
+\infty, & \text { otherwise. }\end{cases}
\end{aligned}
$$

We can then define an auxiliary unconstrained optimization problem for the fund manager, with the returns in the auxiliary asset market defined as

$$
\begin{aligned}
r_{t}^{v} & =r_{t}+\delta\left(\vec{v}_{t}\right) \\
d R_{t}^{v} & =\left(\mu_{R t}+v_{1 t}+\delta\left(\vec{v}_{t}\right)\right) d t+\sigma_{R d, t} d Z_{d t}+\sigma_{R e, t} d Z_{e t} \\
d Z_{e t}^{v} & =\left(v_{2 t}+\delta\left(\vec{v}_{t}\right)\right) d t+d Z_{e t} \\
d Z_{g t}^{v} & =\left(v_{3 t}+\delta\left(\vec{v}_{t}\right)\right) d t+d Z_{g t},
\end{aligned}
$$

for each $\vec{v}_{t}=\left[\begin{array}{lll}v_{1 t} & v_{2 t} & v_{3 t}\end{array}\right]^{\prime}$ in the space $V(\mathcal{K})$ of square-integrable, progressively measurable processes taking values in $\mathcal{K}$. Corresponding to the auxiliary returns processes is an auxiliary state-price density

$$
\frac{d \eta_{t}^{v}}{\eta_{t}^{v}}=-\left(r_{t}+\delta\left(\vec{v}_{t}\right)\right) d t-\left(\vec{\mu}_{R t}-r_{t}+\vec{v}_{t}\right)^{\prime}\left(\sigma_{R t}^{\prime}\right)^{-1} d \vec{Z}_{t}
$$


where

$$
\vec{\mu}_{R t}=\left[\begin{array}{c}
\mu_{R t} \\
0 \\
0
\end{array}\right] ; \quad \sigma_{R t}=\left[\begin{array}{ccc}
\sigma_{R d, t} & \sigma_{R e, t} & 0 \\
0 & 1 & 0 \\
0 & 0 & 1
\end{array}\right] ; \quad \vec{Z}_{t}=\left[\begin{array}{c}
Z_{d t} \\
Z_{e t} \\
Z_{g t}
\end{array}\right] .
$$

The auxiliary unconstrained problem of the representative specialist then becomes

$$
\max _{c_{t}} \mathbb{E}\left[\int_{0}^{+\infty} e^{-\rho t} \log c_{t} d t\right],
$$

subject to the static budget constraint

$$
w_{0}=\mathbb{E}\left[\int_{0}^{+\infty} \eta_{t}^{v} c_{t} d t\right] .
$$

The solution to the original constrained problem is then given by the solution to the unconstrained problem for the $v$ that solves

$$
\begin{aligned}
\vec{v}_{t}^{*} & =\underset{x_{1}=0}{\arg \min }\left\{2 \delta(x)+\left\|\sigma_{R t}^{-1}\left(\vec{\mu}_{R t}-r_{t}+x\right)\right\|^{2}\right\} \\
& =\underset{x_{1}=-x_{2}}{\arg \min }\left\|\sigma_{R t}^{-1}\left(\vec{\mu}_{R t}-r_{t}+x\right)\right\|^{2} .
\end{aligned}
$$

Thus,

$$
v_{t}^{*}=\left[\begin{array}{c}
0 \\
r_{t} \\
r_{t}
\end{array}\right]
$$

Consider now solving the auxiliary unconstrained problem. Taking the first order condition, we obtain

$$
\left[c_{t}\right]: \quad 0=\frac{e^{-\rho t}}{c_{t}}-\lambda \eta_{t}^{v}
$$

or

$$
c_{t}=\frac{e^{-\rho t}}{\lambda \eta_{t}^{v}} .
$$

Substituting into the static budget constraint, we obtain

$$
\eta_{t}^{v} w_{t}=\mathbb{E}_{t}\left[\int_{t}^{+\infty} \eta_{s}^{v} c_{f s} d s\right]=\mathbb{E}_{t}\left[\int_{t}^{+\infty} \frac{e^{-\rho s}}{\lambda} d s\right]=\frac{e^{-\rho t}}{\lambda \rho} .
$$

Thus

$$
c_{t}=\rho w_{t} .
$$


To solve for the fund's optimal portfolio allocation, notice that:

$$
\frac{d\left(\eta_{t}^{v} w_{t}\right)}{\eta_{t}^{v} w_{t}}=-\rho d t
$$

On the other hand, applying Itô's lemma, we obtain

$$
\frac{d\left(\eta_{t}^{v} w_{t}\right)}{\eta_{t}^{v} w_{t}}=\frac{d \eta_{t}^{v}}{\eta_{t}^{v}}+\frac{d w_{t}}{w_{t}}+\frac{d w_{t}}{w_{t}} \frac{d \eta_{t}^{v}}{\eta_{t}^{v}}
$$

Equating the coefficients on the stochastic terms, we obtain

$$
\vec{\alpha}_{f t}=\left(\sigma_{R t} \sigma_{R t}^{\prime}\right)^{-1}\left(\vec{\mu}_{R t}-r_{t}+\vec{v}_{t}\right),
$$

so that

$$
\alpha_{I t}=\frac{\pi_{R t}}{\sigma_{R d, t}^{2}+\sigma_{R e, t}^{2}} .
$$

\section{A.2 Proof of Proposition 3}

Similarly to the specialists' problem, I solve the household problem using the convex duality approach of Cox and Huang (1989) and Cvitanić and Karatzas (1992). Notice, however, that the set of admissible strategies for the household is further restricted by the intermediation constraint, so that:

$$
\mathcal{K}=\left\{\pi \in \mathbb{R}^{3}: \pi_{1} \leq \frac{m \rho^{-1}\left(1-\rho_{h} y_{t}\right)}{y_{t}} ; \pi_{1} \in[0,1] ; \pi_{1}=\pi_{2} ; \pi_{3}=0\right\} .
$$

The results of Cvitanić and Karatzas (1992) apply in this setting as well, so that we can obtain (2.13) for the unconstrained case, and

$$
\alpha_{h t}=\frac{\mu_{R t}^{h}-r_{t}}{\alpha_{I t}\left(\sigma_{R d, t}^{2}+\sigma_{R e, t}^{2}\right)}-\frac{\lambda_{t}+\eta_{1 t}+\eta_{2 t}}{\alpha_{I t}^{2}\left(\sigma_{R d, t}^{2}+\sigma_{R e, t}^{2}\right)}
$$

otherwise. 


\section{B Stationary Distribution Solution}

Recall that the stationary distribution $\varphi$ of the state vector $\left(g_{t}, f_{t}, y_{t}\right)$ solves the partial differential equation (PDE)

$$
\begin{aligned}
0 & =\kappa_{g} \varphi-\kappa_{g}(\bar{g}-g) \frac{\partial \varphi}{\partial g}+\left(\kappa_{g}+2 \kappa\right) \varphi+\left(\kappa_{g}+2 \kappa\right) f \frac{\partial \varphi}{\partial f}-\frac{\partial \mu_{y t}}{\partial y} \varphi-\mu_{y t} \frac{\partial \varphi}{\partial y} \\
& +\frac{\sigma_{g}^{2}}{2} \frac{\partial^{2} \varphi}{\partial g^{2}}+\frac{\sigma_{g}^{2}+\bar{\gamma} \kappa}{2} \frac{\partial^{2} \varphi}{\partial f^{2}}+\sigma_{g}^{2} \frac{\partial^{2} \varphi}{\partial g \partial f}+\frac{1}{2} \frac{\partial^{2} \sigma_{y d, t}}{\partial y^{2}} \varphi+\frac{\sigma_{y d, t}^{2}}{2} \frac{\partial^{2} \varphi}{\partial y^{2}}+\frac{\partial \sigma_{y d, t}^{2}}{\partial y} \frac{\partial \varphi}{\partial y} \\
& -\frac{\bar{\gamma}}{\sigma_{d}} \frac{\partial^{2} \sigma_{y d, t}}{\partial f \partial y} \varphi-\frac{\bar{\gamma}}{\sigma_{d}} \frac{\partial \sigma_{y d, t}}{\partial f} \frac{\partial \varphi}{\partial y}-\frac{\bar{\gamma}}{\sigma_{d}} \frac{\partial \sigma_{y d, t}}{\partial y} \frac{\partial \varphi}{\partial f}-\frac{\bar{\gamma}}{\sigma_{d}} \sigma_{y d, t} \frac{\partial^{2} \varphi}{\partial f \partial y},
\end{aligned}
$$

subject to the boundary conditions

$$
\lim _{y \rightarrow 0} \varphi=0 ; \quad \lim _{y \rightarrow+\infty} \varphi=0 ; \quad \lim _{g \rightarrow \pm \infty} \varphi=0 ; \quad \lim _{f \rightarrow \pm \infty} \varphi=0 ; \quad \int \varphi d y d f d g=1 .
$$

I solve this PDE numerically using a variation of the Method of Lines, which discretizes all but one dimension of the state vector. This reduces the PDE into a system of ordinary differential equations (ODEs) for the remaining variable.

I discretize the state space along the $y_{t}$ and the $f_{t}$ dimensions, and use an implicit method to compute the derivatives. This leaves $g_{t}$ as a continuous variable, for which we will solve the ODEs. By discretizing in the $y_{t}$ and $f_{t}$ dimensions, I can avoid having to compute derivatives of $\mu_{y t}$ and $\sigma_{y d, t}$ in closed form. Index the grid along the $y_{t}$ dimension by $k=1, \ldots, K$, with $y_{1}=0$ and $y_{K}=\bar{y}$, and the grid along the $f_{t}$ dimension by $j=$ $1, \ldots, J$, with $f_{1}=f$ and $f_{J}=\bar{f}$, and denote

$$
\phi_{j k}(g)=\varphi\left(g, f_{j}, y_{f}\right) ; \quad \phi_{j k}^{1}(g)=\frac{\partial \varphi}{\partial g}\left(g, f_{j}, y_{f}\right) .
$$

Then, the first order derivatives can be represented as

$$
\begin{gathered}
\frac{\partial \varphi}{\partial f}=\frac{\phi_{j+1, k}-\phi_{j-1, k}}{2 \Delta f} ; \quad \frac{\partial \varphi}{\partial y}=\frac{\phi_{j, k+1}-\phi_{j, k-1}}{2 \Delta y} ; \quad \frac{\partial \mu_{y t}}{\partial y}=\frac{\mu_{y t}\left(g, f_{j}, y_{k+1}\right)-\mu_{y t}\left(g, f_{j}, y_{k-1}\right)}{2 \Delta y} ; \\
\frac{\partial \sigma_{y d, t}}{\partial y}=\frac{\sigma_{y d, t}\left(g, f_{j}, y_{k+1}\right)-\sigma_{y d, t}\left(g, f_{j}, y_{k-1}\right)}{2 \Delta y} ; \quad \frac{\partial \sigma_{y d, t}}{\partial y}=\frac{\sigma_{y d, t}\left(g, f_{j+1}, y_{k}\right)-\sigma_{y d, t}\left(g, f_{j-1}, y_{k}\right)}{2 \Delta y},
\end{gathered}
$$

where $\Delta f=f_{j+1}-f_{j}$ and $\Delta y=f_{k+1}-f_{k}$, and second order derivatives as

$$
\begin{aligned}
\frac{\partial^{2} \varphi}{\partial f^{2}} & =\frac{\phi_{j+1, k}-2 \phi_{j, k}+\phi_{j-1, k}}{\Delta f^{2}} ; \quad \frac{\partial^{2} \varphi}{\partial y^{2}}=\frac{\phi_{j, k+1}-2 \phi_{j, k}+\phi_{j, k-1}}{\Delta y^{2}} ; \\
\frac{\partial^{2} \varphi}{\partial g \partial f} & =\frac{\phi_{j+1, k}^{1}-\phi_{j-1, k}^{1}}{2 \Delta f} ; \quad \frac{\partial^{2} \varphi}{\partial f \partial y}=\frac{\phi_{j+1, k+1}-\phi_{j+1, k-1}-\phi_{j-1, k+1}+\phi_{j-1, k-1}}{4 \Delta f \Delta y} .
\end{aligned}
$$


Substituting into the PDE, we obtain

$$
\begin{aligned}
0 & =\kappa_{g} \phi_{j k}-\kappa_{g}(\bar{g}-g) \phi_{j k}^{1}+\left(\kappa_{g}+2 \kappa\right) \phi_{j k}+\left(\kappa_{g}+2 \kappa\right) f_{j} \frac{\phi_{j+1, k}-\phi_{j-1, k}}{2 \Delta f} \\
& -\frac{\partial \mu_{y t}}{\partial y} \phi_{j k}-\mu_{y t} \frac{\phi_{j, k+1}-\phi_{j, k-1}}{2 \Delta y}+\frac{\sigma_{g}^{2}}{2} \frac{\partial \phi_{j k}^{1}}{\partial g}+\left(\frac{\sigma_{g}^{2}+\bar{\gamma} \kappa}{2}\right) \frac{\phi_{j+1, k}-2 \phi_{j, k}+\phi_{j-1, k}}{\Delta f^{2}} \\
& +\sigma_{g}^{2} \frac{\phi_{j+1, k}^{1}-\phi_{j-1, k}^{1}}{2 \Delta f}+\frac{1}{2} \frac{\partial^{2} \sigma_{y d, t}}{\partial y^{2}} \phi_{j k}+\frac{\sigma_{y d, t}^{2}}{2} \frac{\phi_{j, k+1}-2 \phi_{j, k}+\phi_{j, k-1}}{\Delta y^{2}}+\frac{\partial \sigma_{y d, t}^{2}}{\partial y} \frac{\phi_{j, k+1}-\phi_{j, k-1}}{2 \Delta y} \\
& -\frac{\bar{\gamma}}{\sigma_{d}} \frac{\partial^{2} \sigma_{y d, t}}{\partial f \partial y} \phi_{j k}-\frac{\bar{\gamma}}{\sigma_{d}} \frac{\partial \sigma_{y d, t}}{\partial f}\left(\frac{\phi_{j, k+1}-\phi_{j, k-1}}{2 \Delta y}\right)-\frac{\bar{\gamma}}{\sigma_{d}} \frac{\partial \sigma_{y d, t}}{\partial y}\left(\frac{\phi_{j+1, k}-\phi_{j-1, k}}{2 \Delta f}\right) \\
& -\frac{\bar{\gamma}}{\sigma_{d}} \sigma_{y d, t}\left(\frac{\phi_{j+1, k+1}-\phi_{j+1, k-1}-\phi_{j-1, k+1}+\phi_{j-1, k-1}}{4 \Delta f \Delta y}\right) .
\end{aligned}
$$

Collecting like terms, we have

$$
\begin{aligned}
0 & =\left(2 \kappa_{g}+2 \kappa-\frac{\partial \mu_{y t}}{\partial y}-\frac{\sigma_{g}^{2}+\bar{\gamma} \kappa}{\Delta f^{2}}+\frac{1}{2} \frac{\partial^{2} \sigma_{y d, t}}{\partial y^{2}}-\frac{\sigma_{y d, t}^{2}}{\Delta y^{2}}-\frac{\bar{\gamma}}{\sigma_{d}} \frac{\partial^{2} \sigma_{y d, t}}{\partial f \partial y}\right) \phi_{j k}-\kappa_{g}(\bar{g}-g) \phi_{j k}^{1} \\
& +\left(\left(\kappa_{g}+2 \kappa\right) f_{j}+\frac{\sigma_{g}^{2}+\bar{\gamma} \kappa}{\Delta f}-\frac{\bar{\gamma}}{\sigma_{d}} \frac{\partial \sigma_{y d, t}}{\partial y}\right) \frac{\phi_{j+1, k}}{2 \Delta f}+\left(-\left(\kappa_{g}+2 \kappa\right) f_{j}+\frac{\sigma_{g}^{2}+\bar{\gamma} \kappa}{\Delta f}+\frac{\bar{\gamma}}{\sigma_{d}} \frac{\partial \sigma_{y d, t}}{\partial y}\right) \frac{\phi_{j-1, k}}{2 \Delta f} \\
& +\left(-\mu_{y t}+\frac{\sigma_{y d, t}^{2}}{\Delta y}+\frac{\partial \sigma_{y d, t}^{2}}{\partial y}-\frac{\bar{\gamma}}{\sigma_{d}} \frac{\partial \sigma_{y d, t}}{\partial f}\right) \frac{\phi_{j, k+1}}{2 \Delta y}+\left(\mu_{y t}+\frac{\sigma_{y d, t}^{2}}{\Delta y}-\frac{\partial \sigma_{y d, t}^{2}}{\partial y}+\frac{\bar{\gamma}}{\sigma_{d}} \frac{\partial \sigma_{y d, t}}{\partial f}\right) \frac{\phi_{j, k-1}}{2 \Delta y} \\
& +\sigma_{g}^{2} \frac{\phi_{j+1, k}^{1}-\phi_{j-1, k}^{1}}{2 \Delta f}+\frac{\sigma_{g}^{2}}{2} \frac{\partial \phi_{j k}^{1}}{\partial g}-\frac{\bar{\gamma}}{\sigma_{d}} \sigma_{y d, t}\left(\frac{\phi_{j+1, k+1}-\phi_{j+1, k-1}-\phi_{j-1, k+1}+\phi_{j-1, k-1}}{4 \Delta f \Delta y}\right) .
\end{aligned}
$$


Table 1: Parameters

\begin{tabular}{cc}
\hline$\sigma_{d}$ & 0.15 \\
$\kappa_{g}$ & 0.0210 \\
$\bar{g}$ & 0.0015 \\
$\sigma_{g}$ & $3.43 \times 10^{-5}$ \\
$\sigma_{e}$ & 0.225 \\
\hline$\kappa$ & 22.22 \\
\hline$m$ & 4 \\
$\rho$ & $1 \%$ \\
$\rho_{h}$ & $1.67 \%$ \\
\hline
\end{tabular}

Notes: Parameters used for numerical illustrations. The parameters of the dividend growth process $\left(\sigma_{d}\right)$, of the long-run mean of dividend growth $\left(\kappa_{g}, \bar{g}, \sigma_{g}\right)$ and of the external signal $\left(\sigma_{e}\right)$ are a version of the Bansal and Yaron (2004) calibration, modified to the setting of this paper. The capacity of the households to process information $\kappa$ is chosen to make zero precision of the external signal in the initial period optimal. The maximal leverage of the specialists, $m$, and the discount rates of the specialists $\rho$ and the households $\rho_{h}$ are taken from He and Krishnamurthy (2013). 


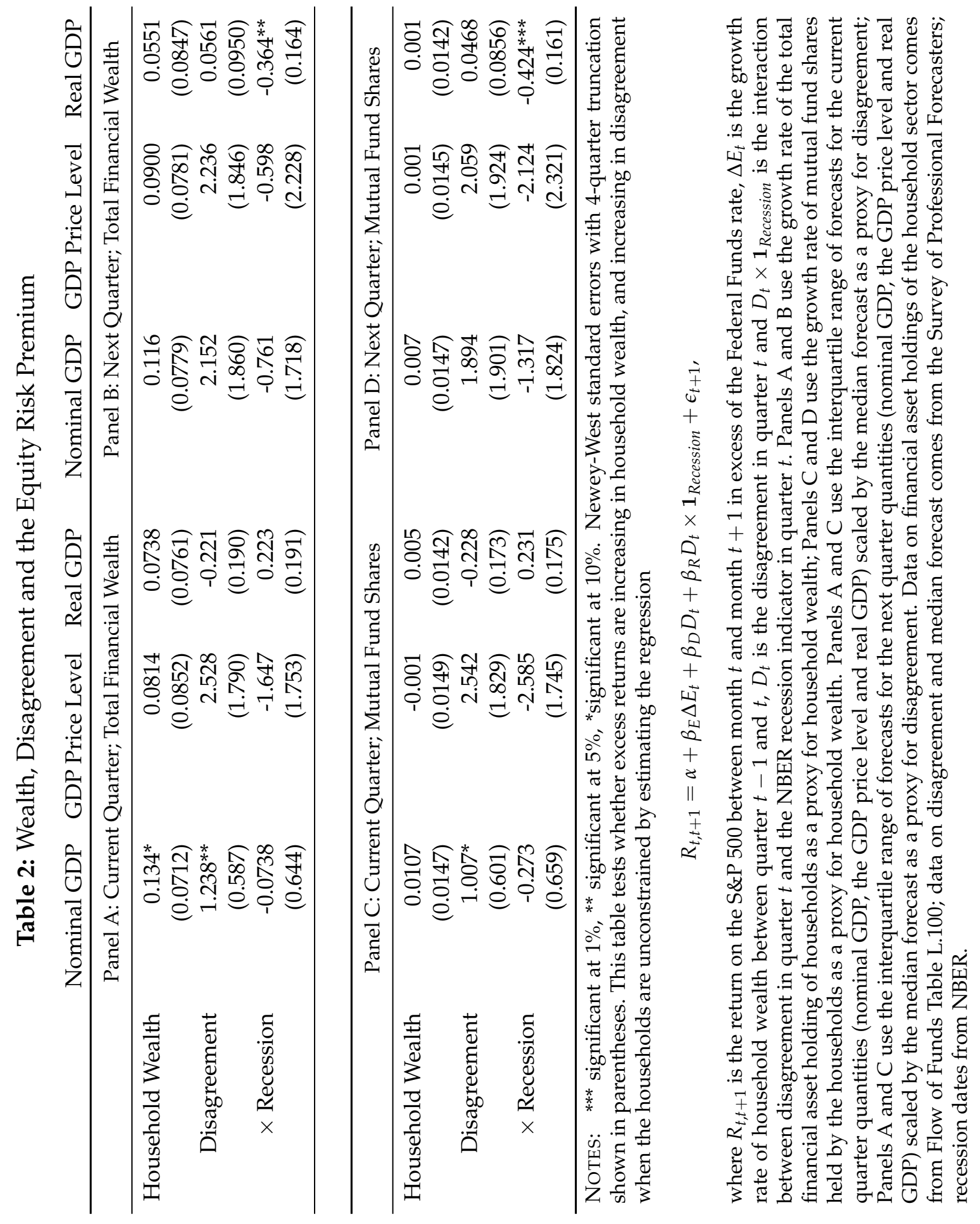



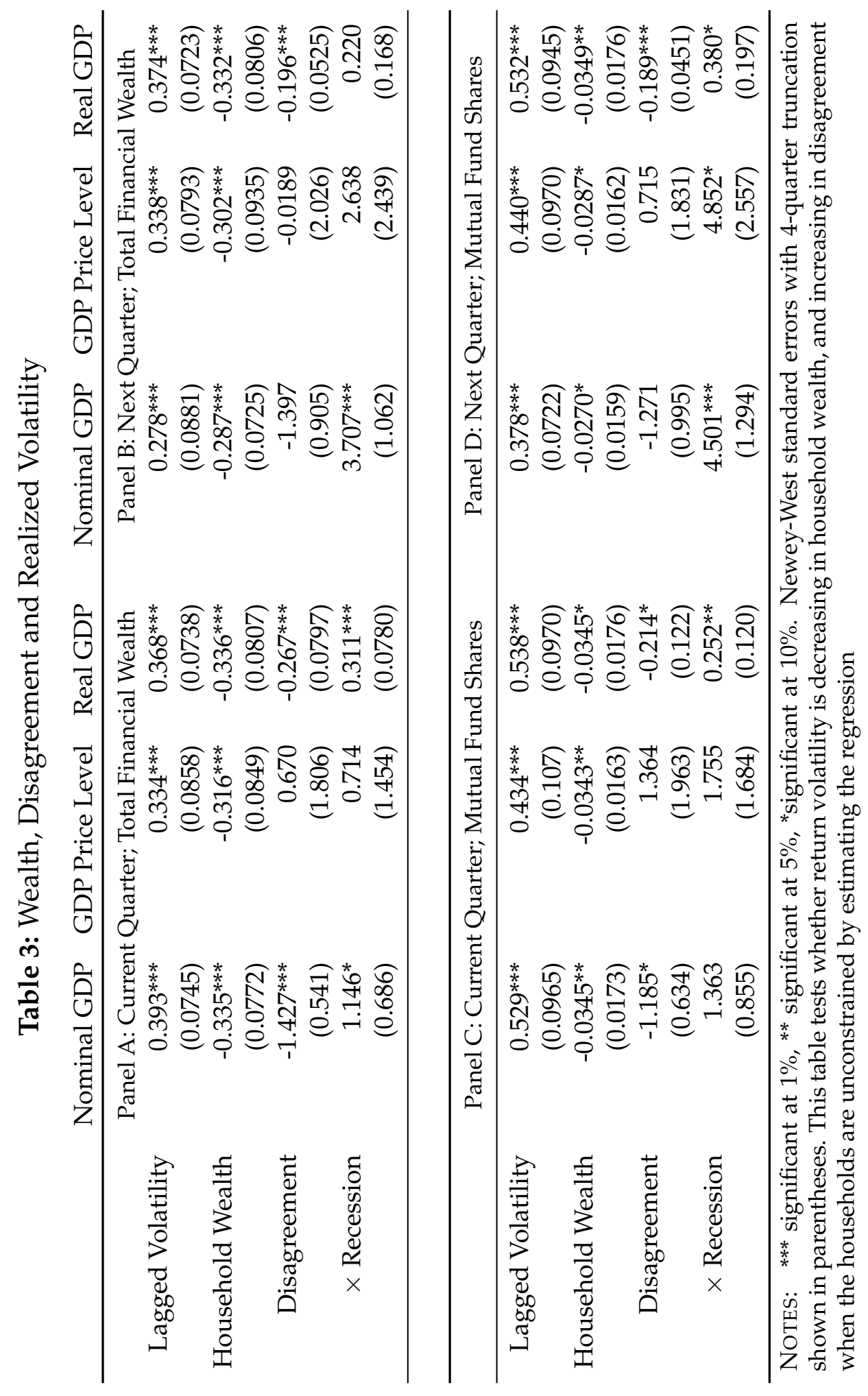

छ च

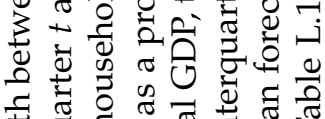
全窇 उ. 正

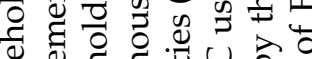

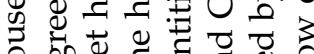

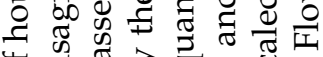

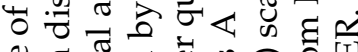
웜

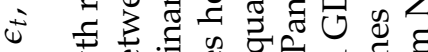
3 运 b. कृ क क

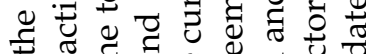
क 出. $\checkmark$ \&

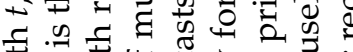

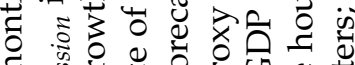
द

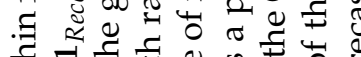

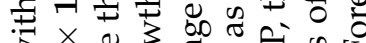

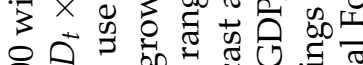

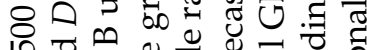

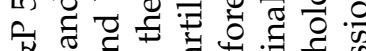
क त 0 व ह

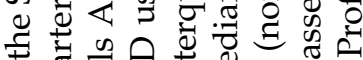

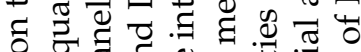
⿷匚 वे छ

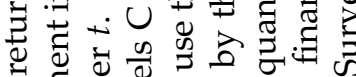

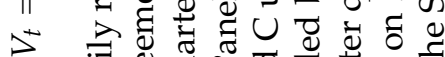
त 5 政

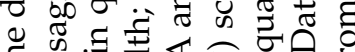
Ð. पू口 P

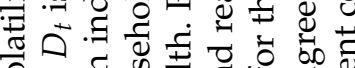
궁

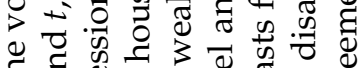
‡ ⿷匚 छ क $\rightarrow$ D

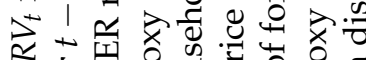

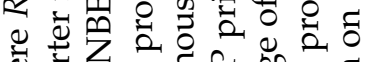

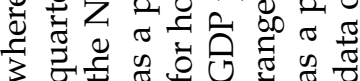



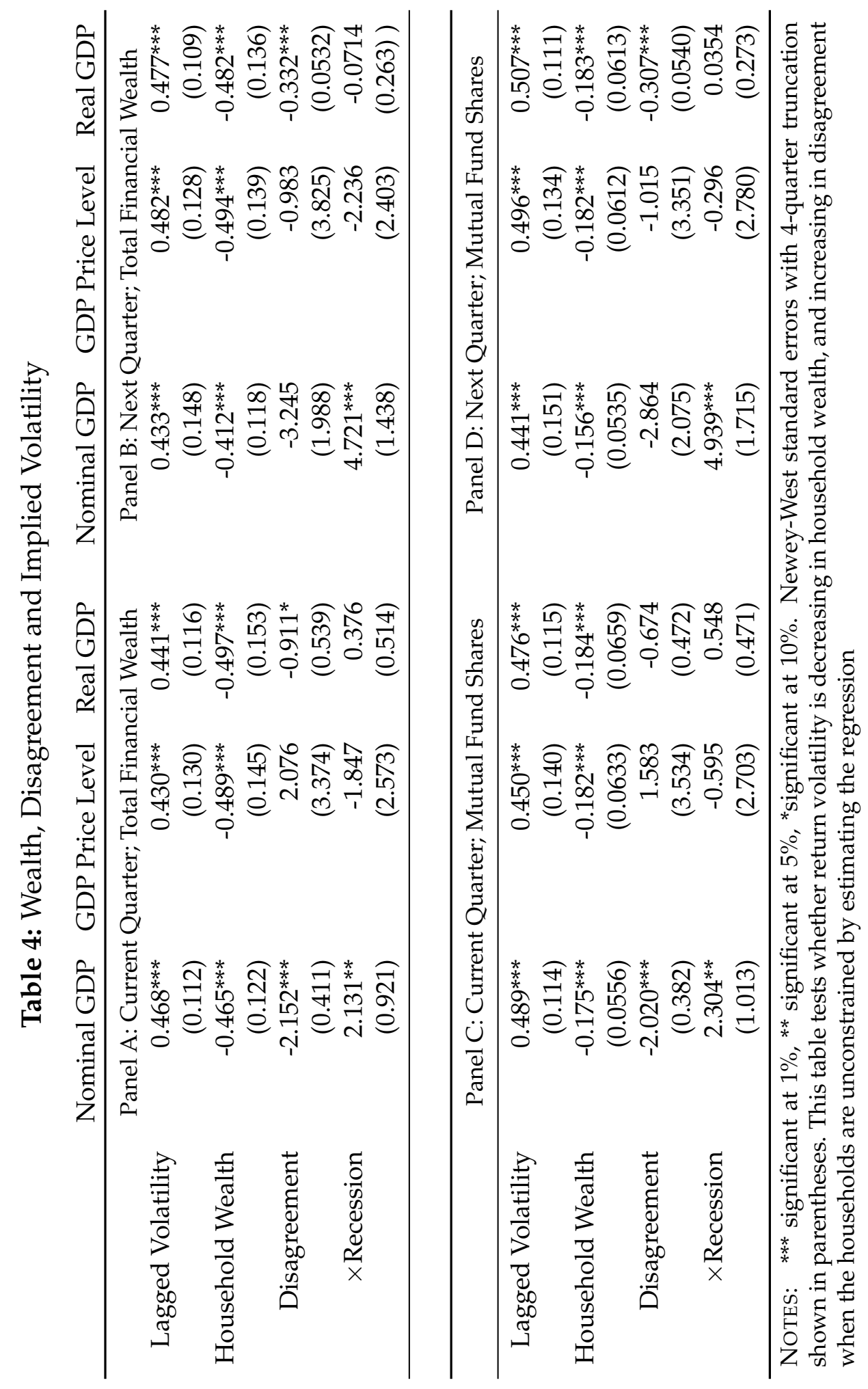

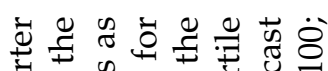

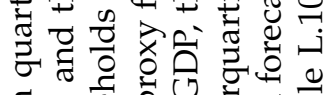

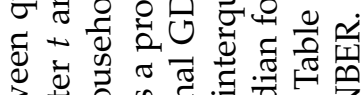

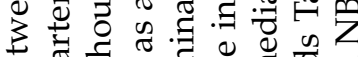

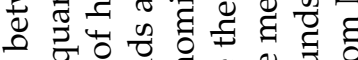
$\mp .500$ 여의 ฮ 3 후웡

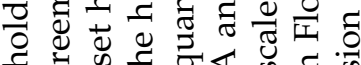
正 至

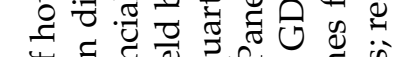

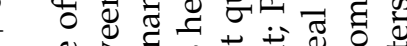

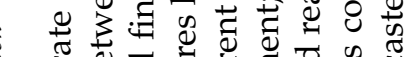

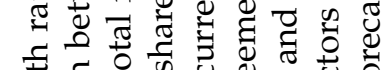

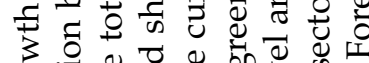
उ.

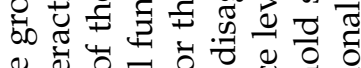

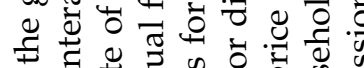

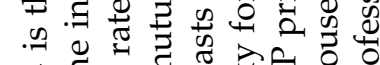

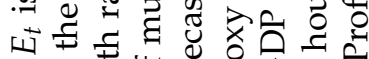

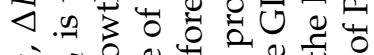

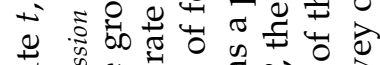
范 तथ

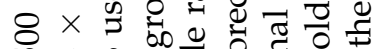
ถ के

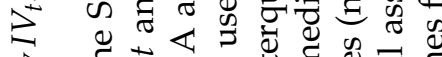
o

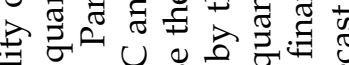

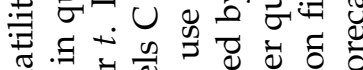

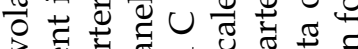
政

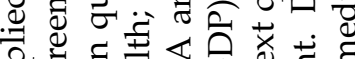
范

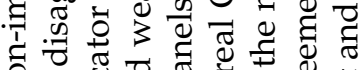
을 O. ॠ. .

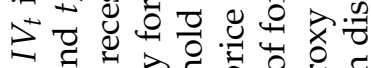

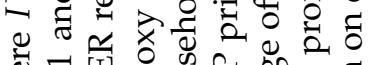

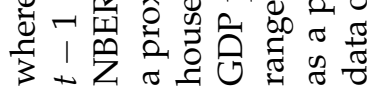


Figure 1. Constrained and Unconstrained Regions

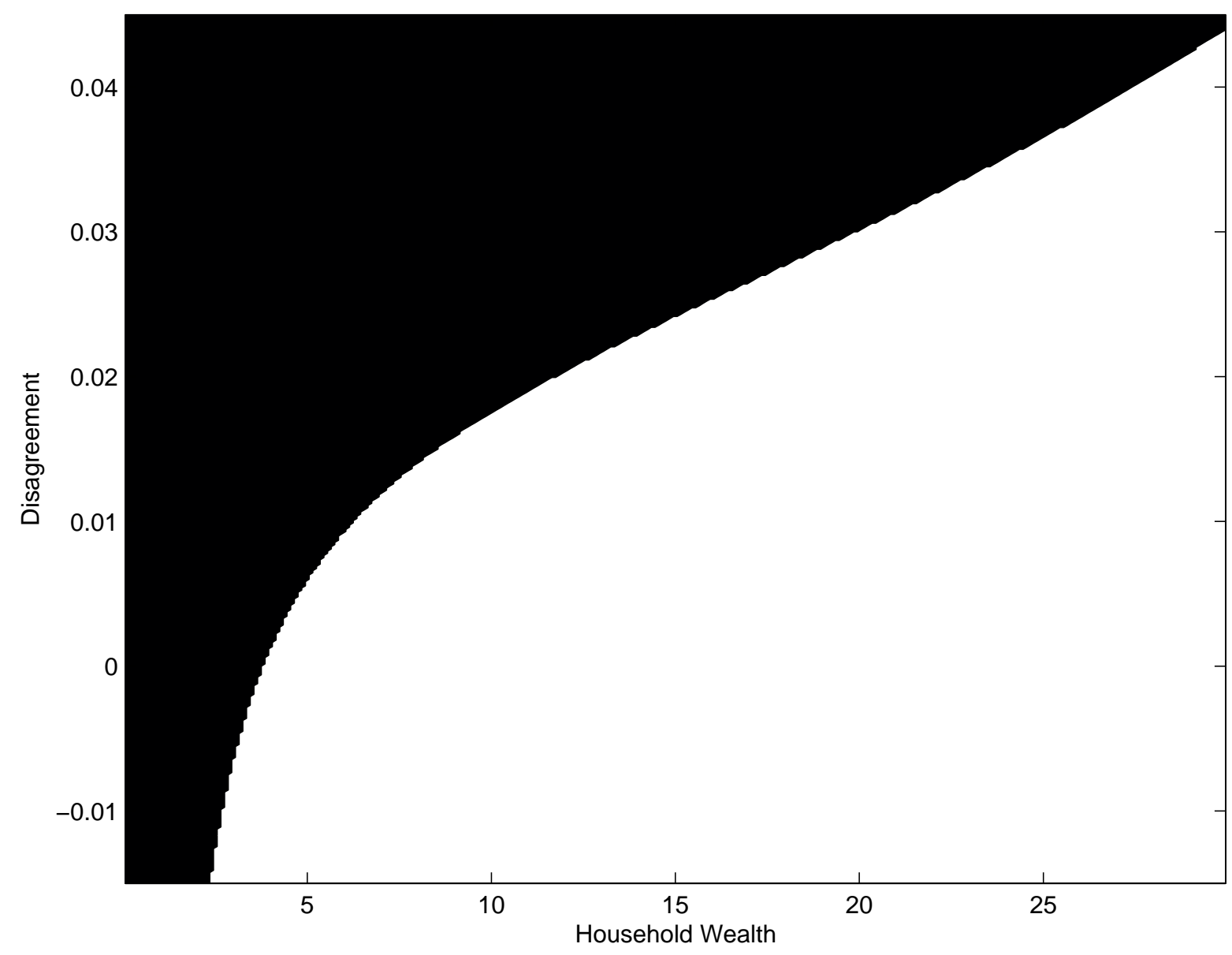

NOTES: Constrained (white) and unconstrained (black) regions of the economy as a function of the scaled household wealth ( $x$-axis) and the disagreement between the households and the specialists (y-axis). Parameters of the economy are given in Table 1. 
Figure 2. Asset Pricing Moments
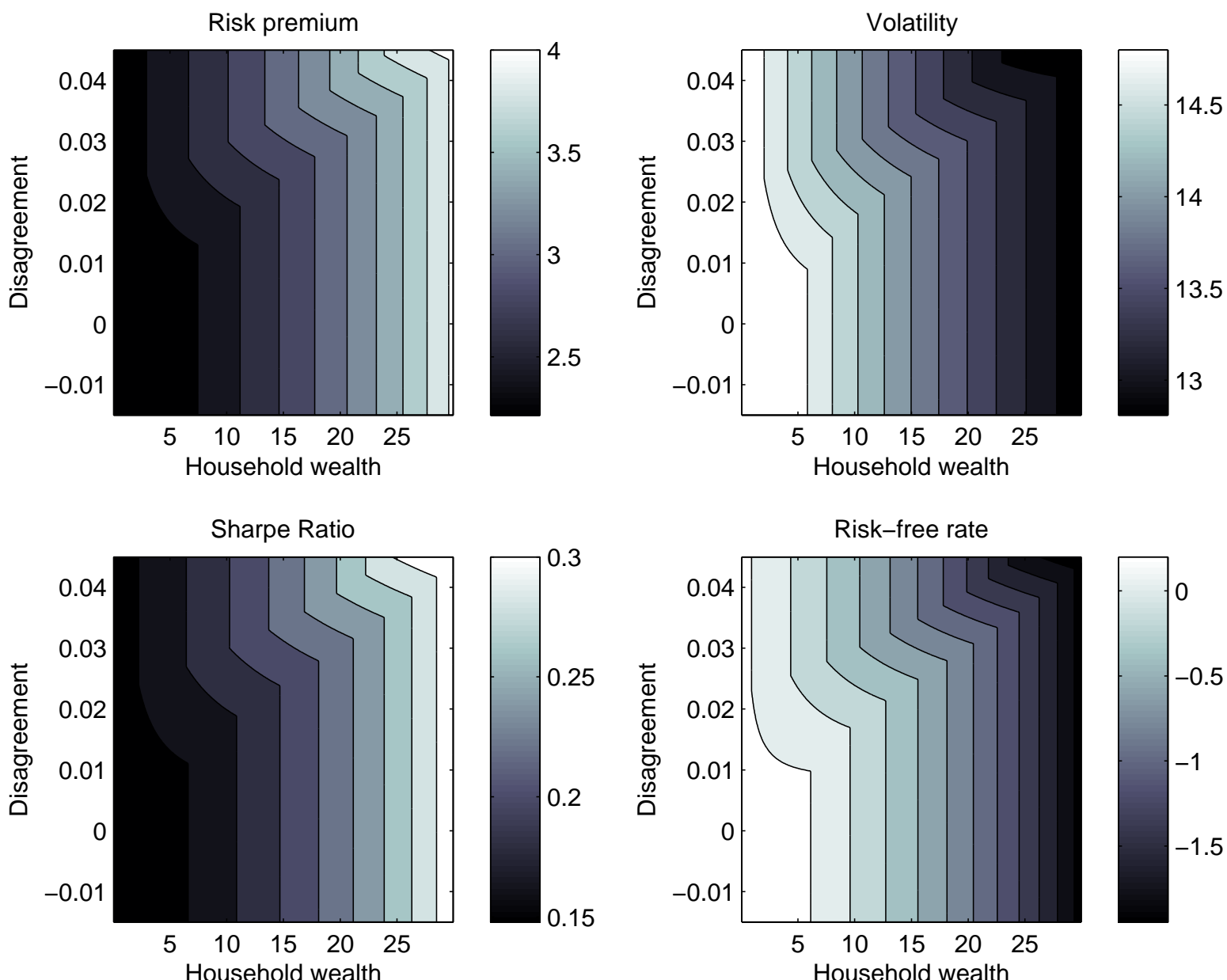

NOTES: The relationship between the equilibrium asset pricing moments and scaled household wealth $y_{t}\left(x\right.$-axis) and the disagreement between households and specialists $f_{t}$ (y-axis). Top left panel: equity risk premium $\pi_{R t}$ (in percent); top right panel: return volatility $\sigma_{R d, t}$ (in percent); bottom left panel: the Sharpe ratio $\pi_{R t} / \sigma_{R d, t}$ on the risky asset; bottom right panel: the equilibrium risk-free rate $r_{t}$ (in percent). Equilibrium asset prices computed using parameters in Table 1. 
Figure 3. Portfolio Allocation
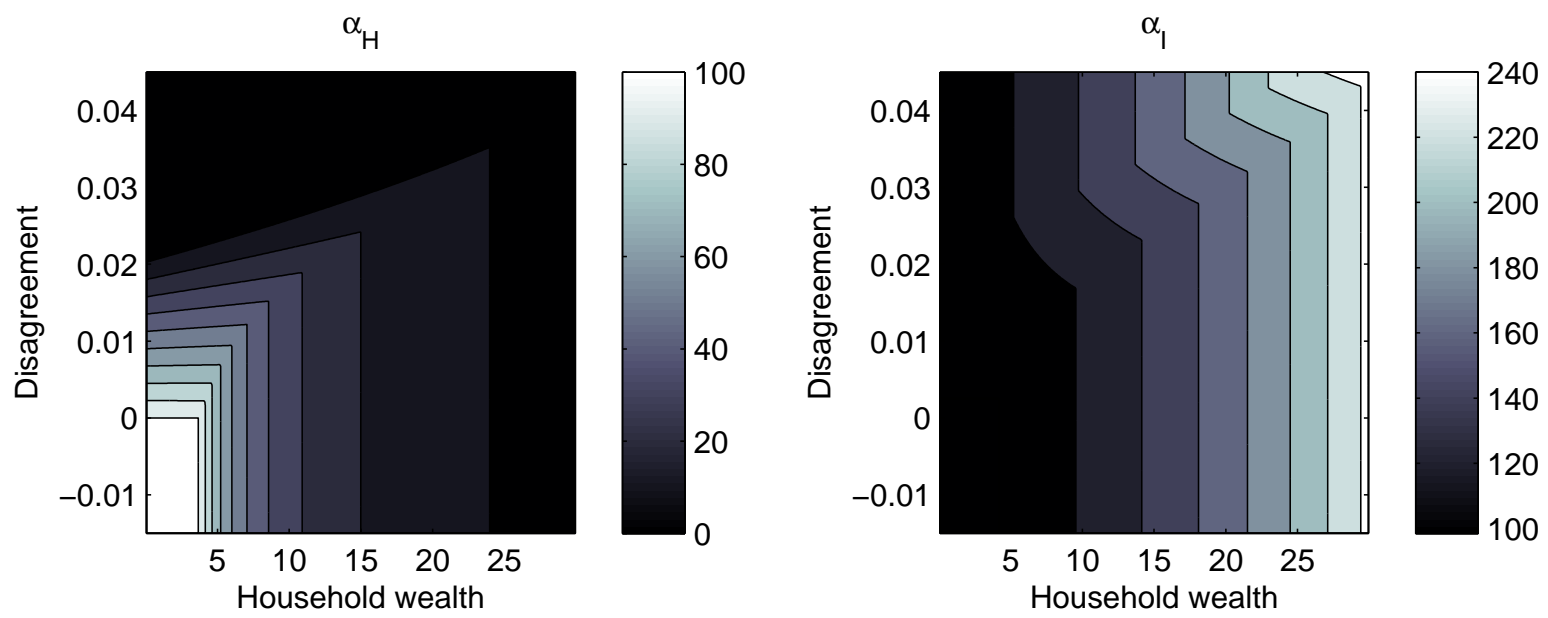

Notes: The relationship between equilibrium portfolio allocation decisions and scaled household wealth $y_{t}$ ( $x$-axis) and the disagreement between households and specialists $f_{t}$ ( $y$-axis). Left panel: fraction of household wealth $\alpha_{h t}$ (in percent) allocated to the intermediary; right panel: fraction of intermediary equity $\alpha_{I t}$ (in percent) allocated to the risky asset. Equilibrium portfolio allocations computed using parameters in Table 1. 


\section{Figure 4. Stationary Density}

(a)

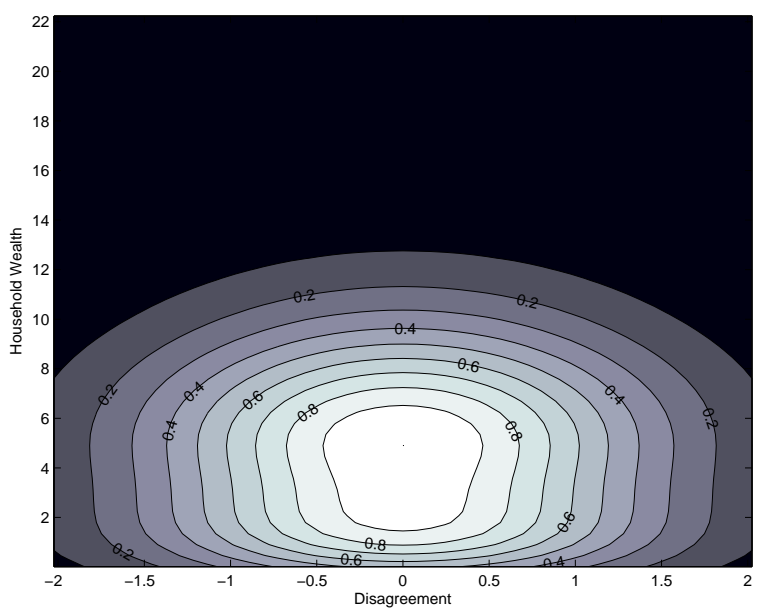

(c)

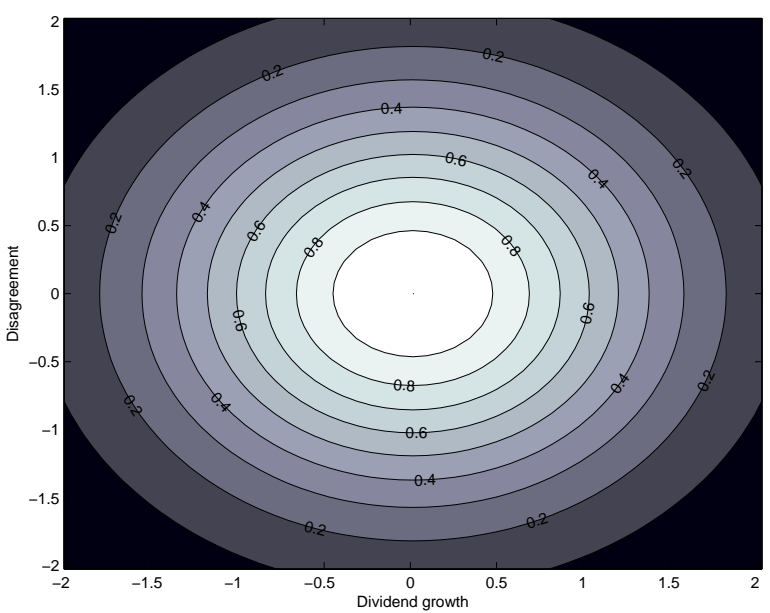

(b)

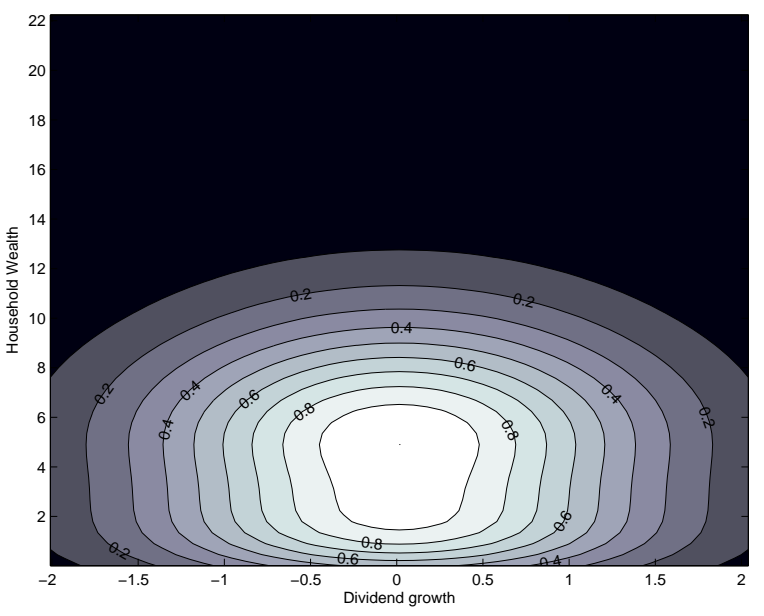

(d)

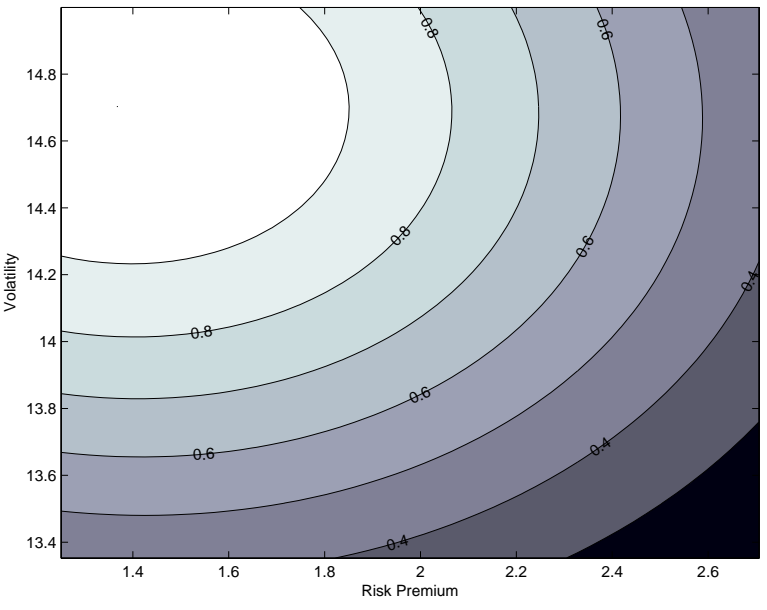

Notes: Bivariate marginal stationary density. Panel (a): Joint density of disagreement ( $x$-axis) and scaled household wealth ( $y$-axis); Panel (b): Joint density of expected dividend growth $(x-$ axis) and scaled household wealth (y-axis); Panel (c): Joint density of expected dividend growth $(x$-axis) and disagreement ( $y$-axis); Panel (d): Joint density of equilibrium risk premium ( $x$-axis) and equilibrium risky asset return volatility ( $y$-axis). Risk premium and return volatility in percentage terms. Densities computed using parameters in Table 1. 
Figure 5. Stationary Distribution, Univariate Marginals
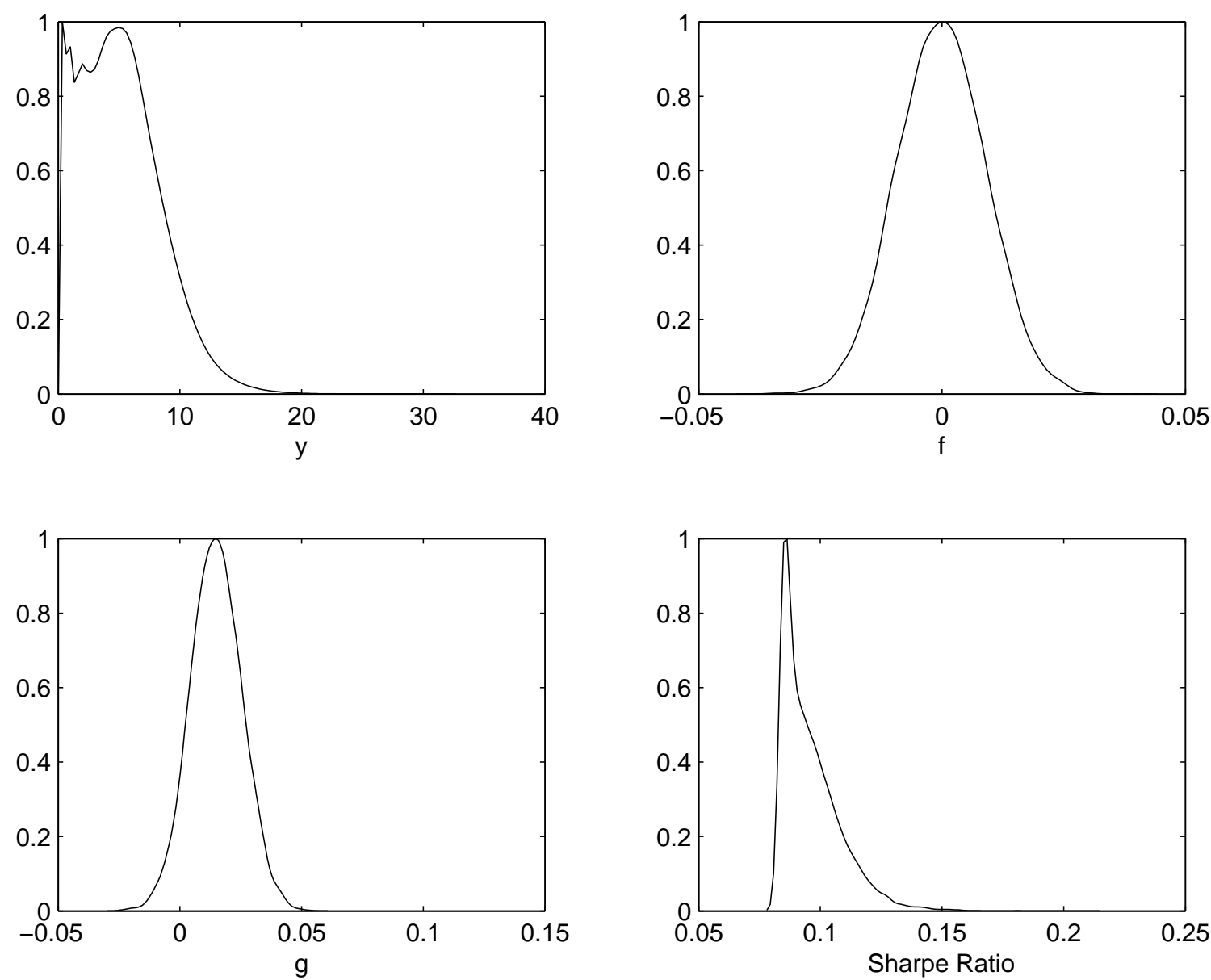

NOTES: Univariate marginal stationary distributions. Top left panel: density of scaled household wealth, $y$; top right panel: density of disagreement between households and specialists, $f$; bottom left panel: density of expected dividend growth, $g$; bottom right panel: density of the equilibrium Sharpe ratio. Densities computed using parameters in Table 1. 
Figure 6. Household Wealth and Disagreement

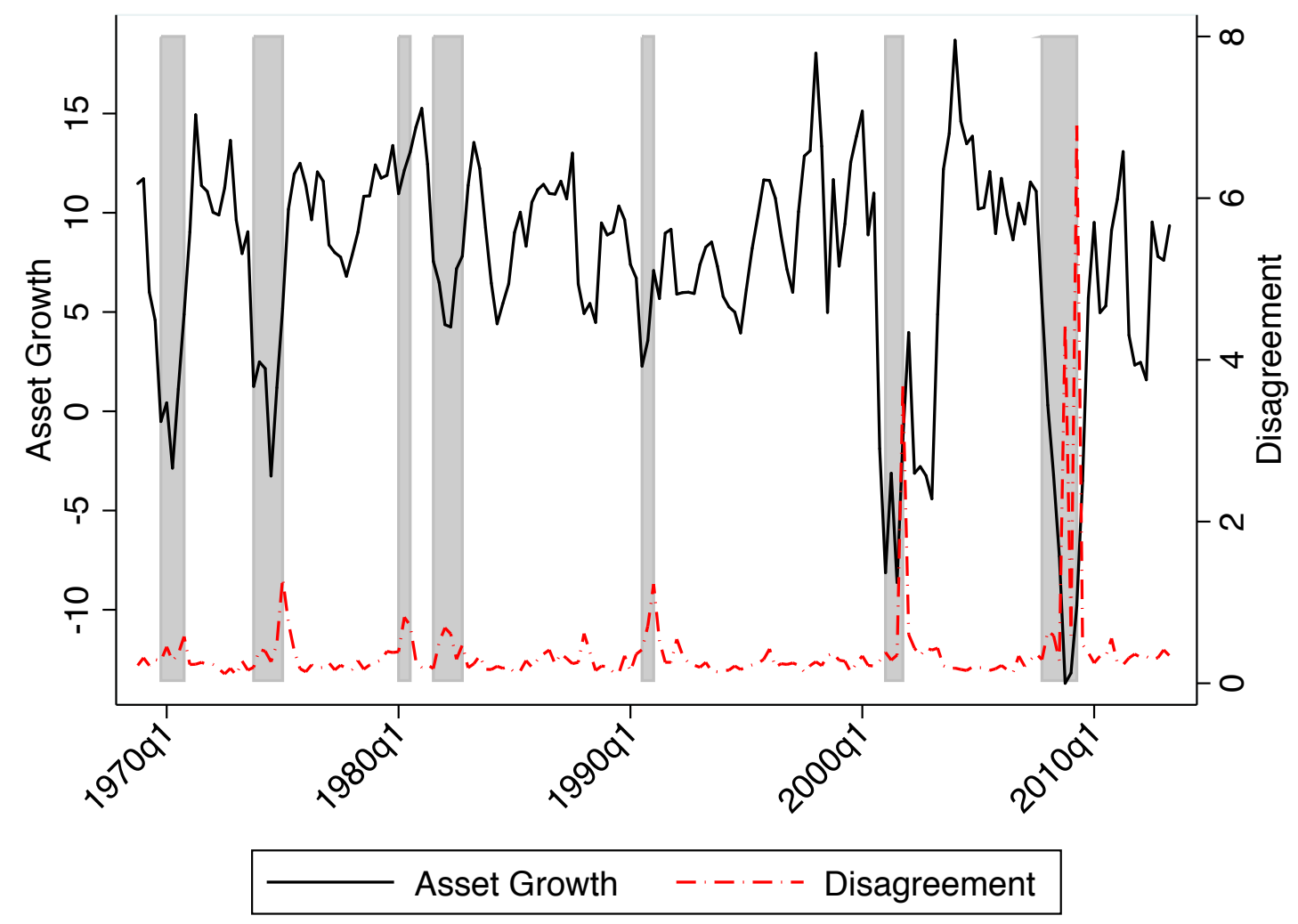

NOTES: Left axis: annual growth rate (percent) of total financial assets held by households; right axis: disagreement over current quarter nominal GDP growth. Data on financial asset holdings of the household sectors comes from Flow of Funds Table L.100. Disagreement is measured as the interquartile range of forecasts scaled by the median forecast; data on disagreement and median forecast comes from the Survey of Professional Forecasters. NBER recessions shaded in grey. 
Figure 7. Returns, Disagreement and Household Wealth
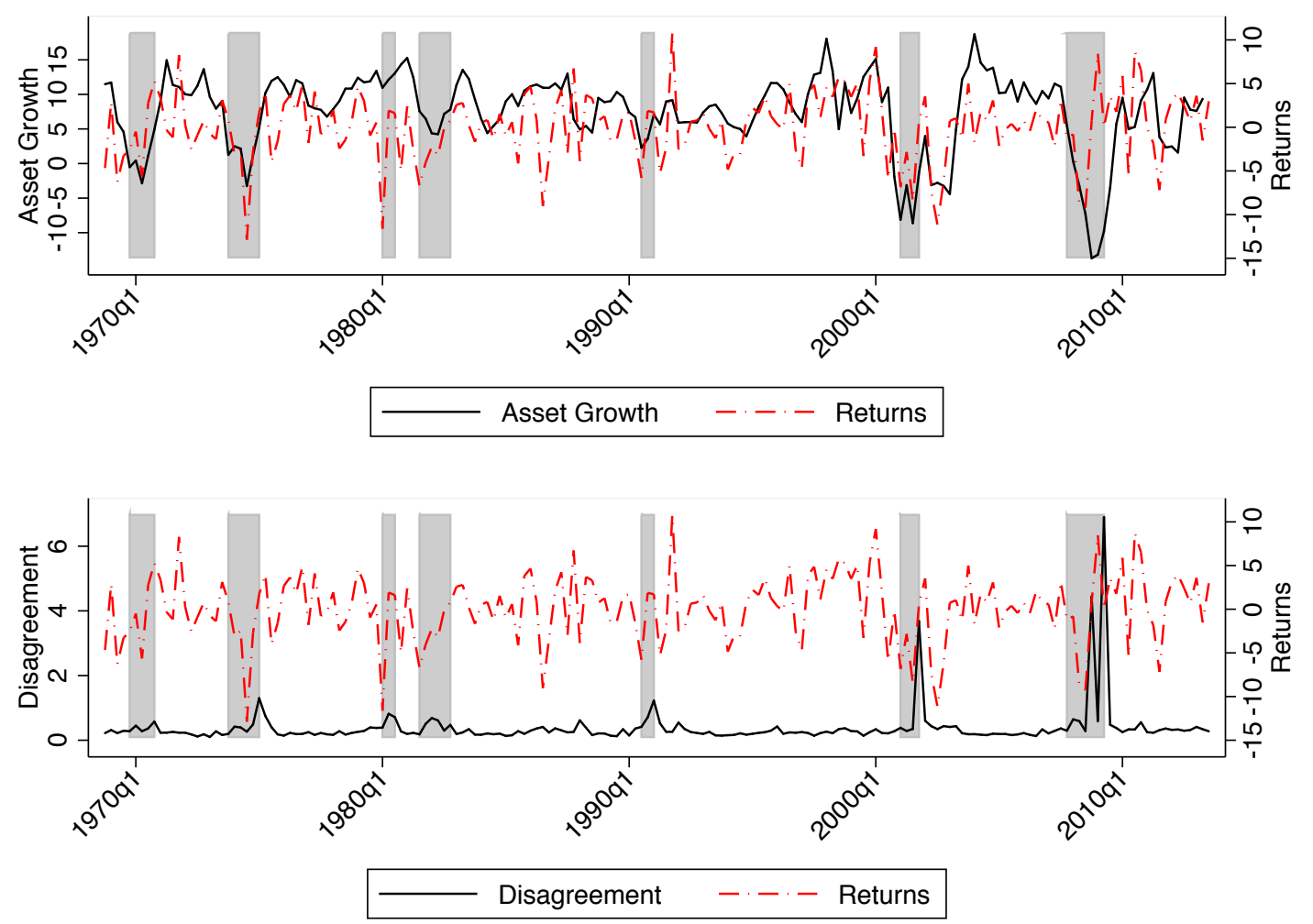

NotES: Top panel: Monthly excess returns on the S\&P 500 (right axis) and annual growth rate (percent) of total financial assets held by households (left axis); bottom panel: monthly excess returns on the S\&P 500 (right axis) and disagreement over current quarter nominal GDP growth. Data on financial asset holdings of the household sectors comes from Flow of Funds Table L.100. Disagreement is measured as the interquartile range of forecasts scaled by the median forecast; data on disagreement and median forecast comes from the Survey of Professional Forecasters. NBER recessions shaded in grey. 
Figure 8. Volatility, Disagreement and Household Wealth
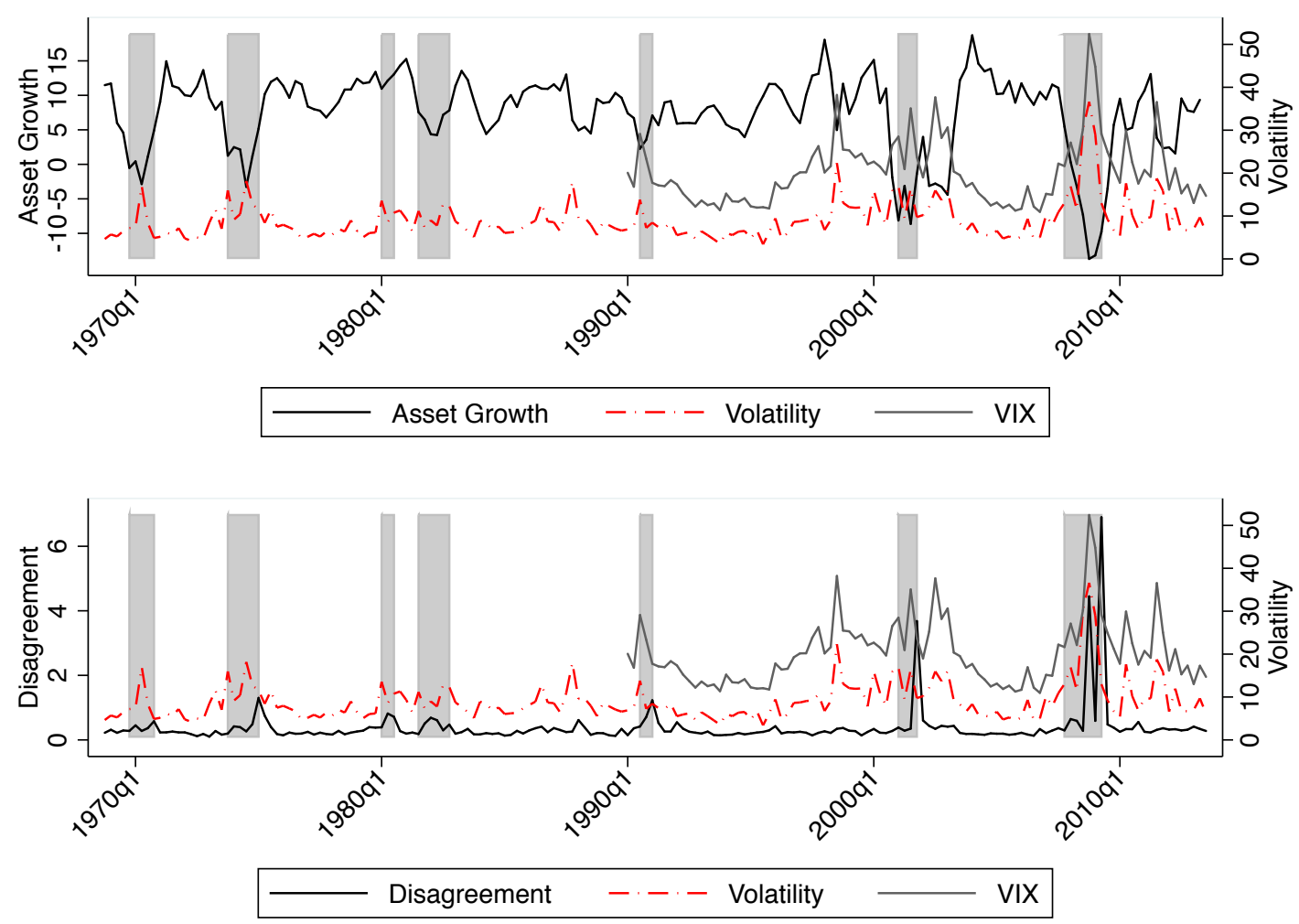

NOTES: Top panel: standard deviation of daily returns within a month on the S\&P 500 (right axis), CBOE VIX index (right axis) and annual growth rate (percent) of total financial assets held by households (left axis); bottom panel: standard deviation of daily returns within a month on the S\&P 500 (right axis), CBOE VIX index (right axis) and disagreement over current quarter nominal GDP growth. Data on financial asset holdings of the household sectors comes from Flow of Funds Table L.100. Disagreement is measured as the interquartile range of forecasts scaled by the median forecast; data on disagreement comes from the Survey of Professional Forecasters. NBER recessions shaded in grey. 